\title{
On the cyclical allocation of risk
}

\author{
Paul Gomme*,a,b, Jeremy Greenwood ${ }^{\mathfrak{c}}$ \\ a Department of Economics, Simon Fraser University, Burnaby, B.C., V5A IS6, Canada \\ ${ }^{\mathrm{b}}$ Research Center on Employment and Economic Fluctuations, Montréal, Qué., H3C 3P8. Canada

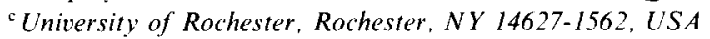

(Received March 1993; final version received July 1993)

\begin{abstract}
A real business cycle model, with two types of agents, workers, and entrepreneurs, is simulated to see if it can account for some stylized facts characterizing postwar U.S. business cycle fluctuations, such as the countercyclical movement of labor's share of income and the acyclical behavior of real wages. It can. There exists an economy-wide market for contingent claims. On this market workers purchase insurance from entrepreneurs, through optimal labor contracts, against losses in income due to business cycle fluctuations. Insurance flows protecting workers against aggregate cyclical risk are calculated to be less than one percent of labor income.
\end{abstract}

Key words: Optimal labor contracts; Arrow-Debreu allocations; Real business cycle theory

JEL classification: $\mathrm{E} 3 ; \mathrm{J} 3$

\section{Introduction}

The cyclical behavior of labor income has long been a topical question for macroeconomists. Two stylized facts concerning the movement of labor income over the business cycle are:

\footnotetext{
${ }^{*}$ Corresponding author.

Advice and helpful comments from James Davies, Jeffrey Lacker, and two anonymous referees are gratefully acknowledged. Also, the Institute of Empirical Macroeconomics at the Federal Reserve Bank of Minneapolis is thanked for the kind hospitality we received. John Knowles provided research assistance for Appendices A and B. Any errors are our own.
} 
(1) Labor's share of income is not constant, but moves countercyclically over the business cycle. Fig. 1 shows, using quarterly data, the movement in labor's share of income over the 1954-1989 sample period. Here, two measures of labor's share of income are used. In the first, labor's share of income is taken to be compensation of employees divided by GNP, both series given in the U.S. National Income and Product Accounts. The correlation between detrended labor's share of income and detrended GNP is $-0.37 .{ }^{1}$ Detrended labor's share of income has a standard deviation of 0.3 percent. This compares to one of 0.9 pereent for the ratio of total consumption to GNP. Observe that there appears to be an upward trend in this measure of labor's share of income over the sample period. At the same time, proprietor's share of income fell over the period. Thus, the rise in labor's share may reflect a decline in the importance of sole proprietorships and partnerships relative to the corporate and government sectors. The second measure of labor's share of income attempts to control for this effect by netting proprietor's income out of GNP. The correlation between labor's share of income and GNP now becomes -0.22 . The countercyclical movement in labor's share of income was also found in a sample of eight OECD countries - the details are in Appendix A.

(2) The real wage does not appear to move systematically over the business cycle. Two measures for the real wage are used. The first measure uses data from the national income accounts to construct an index of the real wage. Here, the real wage is defined to be compensation of employees per aggregate hour worked in the economy. The correlation between the detrended real wage and GNP is -0.40 . The second measure is an index of real compensation per hour paid in the business sector published by the U.S. Bureau of Labor Statistics. ${ }^{2}$ The real wage now moves procyclically, having a correlation with output of 0.36 . Thus, the cyclical pattern of wages appears to be sensitive to the particular definition of wages used. The consensus opinion seems to be that the real wage shows no strong cyclical pattern. This is what is found here for a sample of eleven OECD countries - again, see Appendix A. The observed acyclicality of real wages is often referred to as the Dunlop-Tarshis observation. ${ }^{3}$

\footnotetext{
${ }^{1}$ The data were detrended using the Hodrick-Prescott filter. The correlation between the first measure of labor's share of income and GNP is -0.55 when the data is first differenced instead. For the second measure, the number is -0.53 .

${ }^{2}$ The second measure for the real wage is series LBCP7 contained in Citibase.

${ }^{3}$ The stated purpose of the research by Dunlop (1938) and Tarshis (1939) was to investigate Keynes's claim that real and nominal wages tended to move in opposite directions. These papers are early examples of studies attempting 'to bring theory and observation closer together' (Dunlop, 1938, p. 413). Neither author found Keynes's assertion to be borne out statistically. This casts doubt on
} 
The purpose of this paper will be to address these facts from the perspective of real business cycle theory as advanced by Kydland and Prescott (1982) and Long and Plosser (1983). Real business cycle models have been able to capture many features of the U.S. business cycle remarkably well, such as the postwar correlation structure between output, consumption, investment, and hours worked. By and large, though, the real business cycle literature has been silent on the movement of labor income over the business cycle. Instead the prototypical real business cycle model has a representative agent with isoelastic preferences, defined over consumption and leisure, who produces output according to a Cobb-Douglas production technology that uses capital and labor. With this formulation, labor's share of income is constant over the business cycle. Given that the only source of fluctuations in the model is Hicks-neutral technology shocks, the real wage (marginal product of labor) is strongly procyclical. Skeptics have pointed to these facts when casting doubt on the utility of the real business cycle paradigm. To quote Summers (1986, p. 25), this work 'does not resolve - or even mention - the empirical reality ... that consumption and leisure move in opposite directions over the business cycle with no apparent procyclicality of real wages. It is finessed by ignoring wage data.

The starting point for the current analysis is the observation that a given set of real allocations for an economy may be consistent with a wide variety of institutional arrangements. In particular, following Azariadis (1978) it will be assumed that built into labor income is an insurance component designed to provide workers with some degree of protection against business cycle fluctuations. This insurance component of labor income inserts a wedge between the marginal product of labor and measured real wages. As a theoretical proposition, it has been suggested by Wright (1988) and others that labor contracting may explain the apparent acyclical movement of real wages. It remains to be seen, however, whether the introduction of optimal labor contracting into a real business cycle model can account, quantitatively, for the observed pattern of fluctuations in labor income.

\footnotetext{
certain aspects of the General Theory. Dunlop also documented (Table II, p. 419) a failure of the real wage to move countercyclically, again drawing in question components of the General Theory. Because of the latter finding by Dunlop, the failure of the real wage to exhibit a strong pattern of cyclical movement has come to be known as the Dunlop-Tarshis observation. Recently, Christiano and Eichenbaum (1992) have reinterpreted the Dunlop-Tarshis observation as the absence of a strong correlation between real wages and hours worked. Interestingly, Tarshis (1939, p. 154) reported a strong negative correlation between wages and hours worked. For the postwar period, the correlation between the first measure of real wages and hours worked is -0.63 , while for the second it is 0.21 . Conventional wisdom seems to be that real wages and hours worked are not strongly correlated.
} 
Labor's Share of GNP: Measure 1

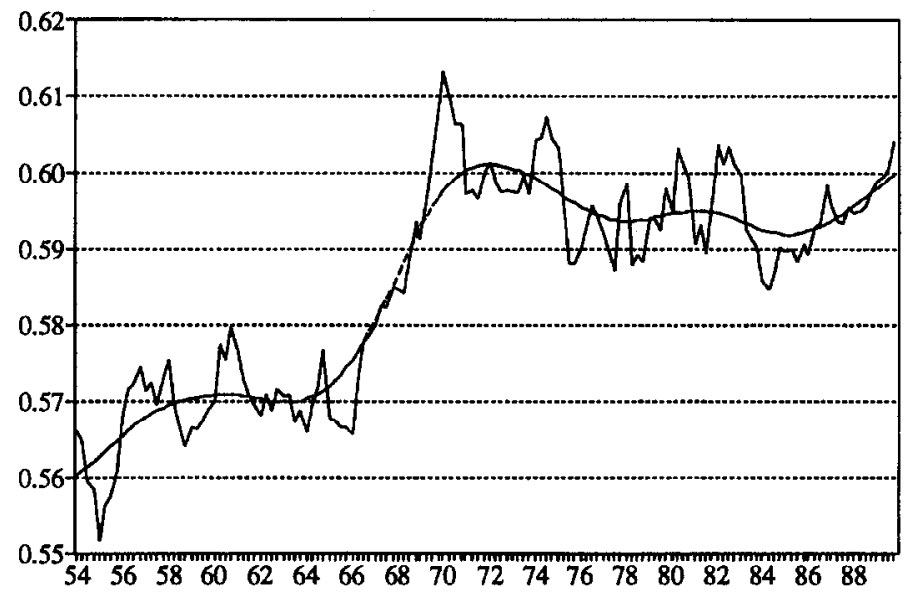

Labor's Share of GNP: Measure 2

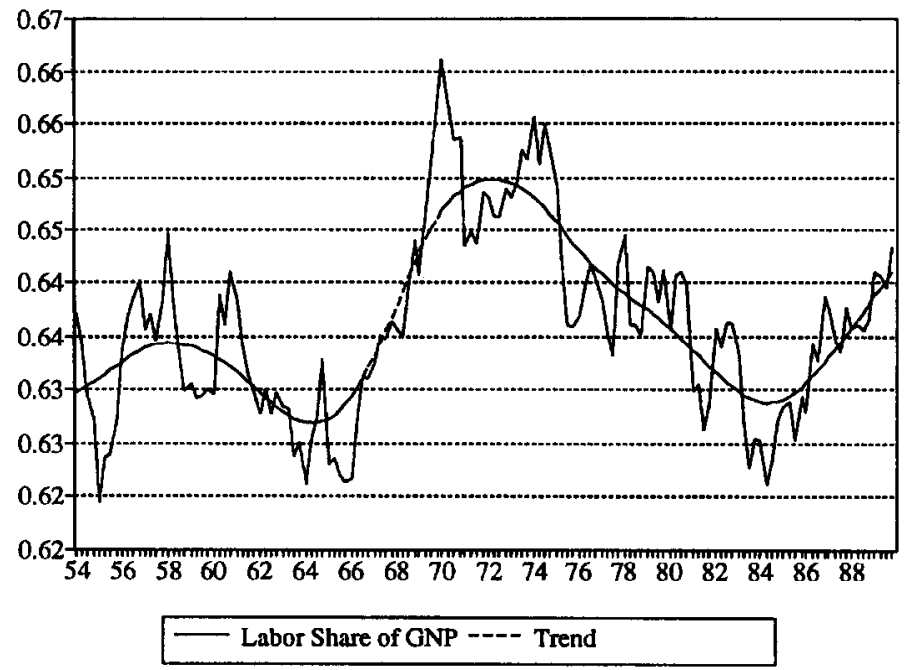

Fig. 1. Labor's share of GNP.

To conduct the analysis, a real business cycle model with heterogeneous agents is constructed. ${ }^{4}$ Specifically, in the model there are two types of agents, viz workers and entrepreneurs. Agents have preferences that are formulated in line with Epstein's (1983) notion of stationary cardinal utility. This allows (the deterministic version of) the model to possess a unique, invariant distribution of 
wealth across agents. ${ }^{5}$ Preferences of this type have also been used by Mendoza (1991) who simulates an open economy real business cycle model. In any given period, workers and entrepreneurs are free to transact on the economy-wide market for contingent claims. The quantity of contingent claims transacted in each possible state of the world is computed. This Arrow-Debreu equilibrium is consistent with many different trading arrangements. Attention is directed here toward an optimal labor contracting scheme that supports the Arrow-Debreu allocations. The optimal labor contract is priced, and its implications for the movement of labor income over the business cycle specified. Next, the constructed model is parameterized, calibrated, and simulated to see whether it can mimic the movements in labor income that are found in the data; it can. Finally, how much risk gets shifted from workers to entrepreneurs? A metric of this is constructed for both the model and the U.S. data. They turn out to be close in magnitude.

The current work complements two other papers on risk sharing by Cho and Rogerson (1987) and Danthine and Donaldson (1992). Both of these studies investigate the implication of labor contracting for the relative volatility of hours and productivity over the business cycle. Neither focus on the implications of labor contracting for the cyclical properties of labor income. Danthine and Donaldson construct a non-Walrasian real business cycle model of labor contracting that is substantially different from the equilibrium model being developed here. The model can mimic the relative volatilities of hours and productivity that are observed in the U.S. data. Cho and Rogerson examine the effects of risk sharing in a real business cycle model where entrepreneurs are risk neutral. The assumption of risk-neutral entrepreneurs allows a simple aggregation procedure to be employed so that the model can be reformulated in terms of a representative agent's planning problem. They find that such a model is helpful in explaining the relative volatilities of hours and productivity, but that it mimics poorly the behavior of other variables, such as consumption and investment, due to the risk neutrality assumption for entrepreneurs. The current study focuses on computing a fully decentralized Arrow-Debreu equilibrium where all agents are risk-averse.

\footnotetext{
${ }^{4}$ Rebelo (1988) discusses how heterogeneous agent economies can be computed for linear-quadratic settings. His technique involves finding the weights for a central planner's problem that will generate the competitive equilibrium under study. Presumably the trades in contingent claims, or other assets, that support the equilibrium could then be backed out. This is different from the tack taken here where the decentralized competitive equilibrium, including the flow of transactions undertaken on contingent claims markets, is solved for directly.

${ }^{5}$ Lucas and Stokey (1984, p. 169) state: "The hypothesis of increasing impatience ... appears to be an essential component that any theory ... must possess if it is to generate dynamics under which wealth distributions converge to determinate, stationary equilibria in which all agents have positive wealth and consumption levels.'
} 
The remainder of this paper is organized as follows: In the next section an outline of the economic environment is presented. Then, in Section 3, the optimization problems faced by individual agents are cast and the economy's general equilibrium is characterized. Some optimal contract schemes that support the Arrow-Debreu equilibrium are discussed in Section 4. The model is parameterized and calibrated in Section 5. The findings from the simulation experiments are reported in Section 6. First, the ability of the model to match a set of stylized facts characterizing U.S. business cycle fluctuations is assessed. Next, the role that the endogenous discount factor plays in promoting intertemporal substitution, and hence in amplifying aggregate disturbances, is studied. Third, the section ends with an attempt to quantify the amount of aggregate risk that gets shifted from workers to entrepreneurs. Finally, some concluding remarks are made in the last section.

\section{The economic environment}

Consider a perfectly competitive economy inhabited by two types of agents, viz workers and entrepreneurs. There are $n$ times more workers than entrepreneurs, with the number of entrepreneurs being normalized to one. Each entrepreneur operates a constant-returns-to-scale production process which produces output in period $t, y_{t}$, as specified by

$$
y_{t}=F\left(k_{t}, n l_{t}, h_{t} ; \lambda_{t}\right),
$$

where $k_{t}$ is his stock of capital in period $t, n l_{t}$ is the total amount of period- $t$ labor services hired from workers, $h_{t}$ is the entrepreneur's labor effort in this period, and $\lambda_{t}$ is a technology shock. The technology shock $\lambda_{t}$ evolves according to

$$
\lambda_{t}=\lambda_{t-1}^{\rho} \varepsilon_{t}, \quad 0<\rho<1,
$$

where $\varepsilon_{t}$ is drawn from the finite set $A=\left\{\varepsilon^{1}, \varepsilon^{2}, \ldots, \varepsilon^{q}\right\}$ according to the distribution function $\mathrm{E}\left(\varepsilon_{t}\right)$. Observe that, conditional on a value for $\lambda_{\mathrm{T}-1}$, $\lambda_{1}$ will be drawn from the finite set $L_{t}=\left\{\lambda_{t}^{1}, \lambda_{t}^{2}, \ldots, \lambda_{t}^{q}\right\}$ where $\lambda_{t}^{j}=\left(\lambda_{t-1}\right)^{\rho} \varepsilon_{t}^{j}$. An entrepreneur's capital accumulation is governed by the law of motion

$$
k_{t+1}=(1-\delta) k_{t}+i_{t},
$$

where $\delta$ is the depreciation rate and $i_{t}$ is gross investment at time $t$.

The representative entrepreneur in the model desires to maximize the expected value of his lifetime utility, $\underline{Z}$, as given by

$$
\mathrm{E}[\underline{Z}]=\mathrm{E}\left\{\sum_{t=0}^{\infty}\left[\prod_{\tau=0}^{1-1} \mathrm{e}^{-\phi\left(Z\left(x_{t}, 1-h_{t}\right)\right)}\right] Z\left(x_{t}, 1-h_{t}\right)\right\}
$$


where $x_{t}$ and $1-h_{t}$ represent his period-t consumption of goods and leisure. Here $Z\left(x_{t}, 1-h_{t}\right)$ represents the entrepreneur's momentary utility function for period $t$. It will be postulated that the function $Z$ is negative, increasing, and 'more than strictly concave' in the sense that $\ln (-Z)$ is strictly convex. The term $\prod_{\tau=0}^{t-1} \mathrm{e}^{-\phi\left(Z\left(x_{t}, 1-h_{\mathrm{t}}\right)\right)}$ is the endogenous discount factor attached to the period- $t$ momentary utility function. The function $\phi$ is assumed to be positive, increasing, and strictly concave. The conditions imposed on $Z$ and $\phi$ guarantee that the agent's lifetime utility function, $Z$, is both increasing and strictly concave. ${ }^{6}$ Note that, by construction, an increase in the period- $\tau$ utility will cause the agent to discount future periods (all $t>\tau$ ) more heavily, or to become more impatient.

Similarly, the representative worker in the model desires to maximize his expected lifetime utility, $\mathrm{E}[\underline{U}]$, as given by

$$
\mathrm{E}[\underline{U}]=\mathrm{E}\left\{\sum_{t=0}^{\infty}\left[\prod_{t=0}^{t-1} \mathrm{e}^{-v\left(U\left(c_{,}, 1-l,\right)\right)}\right] U\left(c_{t}, 1-l_{t}\right)\right\} .
$$

The worker's period- $t$ momentary utility function, $U\left(c_{t}, 1-l_{t}\right)$, is defined over his consumption, $c_{t}$, and leisure, $1-l_{t}$, in this period and is assumed to have the standard properties. The term $\prod_{\tau=0}^{r-1} \mathrm{e}^{-v\left(I /\left(c_{t}, 1-l_{8}\right)\right)}$ is the endogenous discount factor that the worker attaches to period- $t$ utility. The functions $U$ and $v$ are assumed to satisfy the same properties as $Z$ and $\phi$. Observe that workers and entrepreneurs can differ from one another in their attitudes toward both accumulation and risk.

Both workers and entrepreneurs may desire to insure themselves against aggregate fluctuations due to technology shocks. It will be assumed that all agents are free to participate on an economy-wide contingent claims market. Let $s_{t}$ denote the state-of-the-world in period $t$, which is postulated to be governed by the transition function $S\left(s_{t} \mid s_{t-1}\right)$ - a precise definition of $s_{t}$ and a justification for the assumed form of its law of motion will be provided later. Now let the price in period $t$ of a unit of $t+1$ consumption contingent on the event $\lambda_{t+1}$ occurring, given that the current state-of-the-world is $s_{t}$, be represented by $p_{t}\left(\lambda_{t+1}\right)$. Note that, conditional upon the current state, $s_{t}$, the only source of uncertainty next period in the economy is from the technology shock, $\lambda_{t+1}$. The quantity of such claims purchased by workers and entrepreneurs will be denoted by $b_{t+1}\left(\lambda_{t+1}\right)$ and $a_{t+1}\left(\lambda_{t+1}\right)$, respectively. Thus, in each period $t$, workers and entrepreneurs purchase a portfolio of claims represented by

\footnotetext{
${ }^{6}$ This follows from a straightforward modification of the argument made in Epstein (1983, Lemma 1). Also, a minor notational point concerning the definition of the discount factor: Let $\prod_{\mathrm{r}=0}^{t-1} \equiv 1$ for $t<1$.
} 
$\dot{b}_{t+1}\left(\dot{\lambda}_{t+1}\right) \equiv\left[b_{t+1}\left(\lambda_{t+1}^{1}\right), \ldots, b_{t+1}\left(\lambda_{t+1}^{q}\right)\right] \quad$ and $\quad \vec{a}_{t+1}\left(\vec{\lambda}_{t+1}\right) \equiv\left[a_{t+1}\left(\lambda_{t+1}^{1}\right), \ldots\right.$, $\left.a_{t+1}\left(\lambda_{t+1}^{q}\right)\right]$. Finally, define $\Lambda\left(\lambda_{t+1} \mid s_{t}\right)$ to be the marginal density function for $\lambda_{t+1}$, conditional on $s_{t}$, that is associated with the transition function $S\left(s_{t+1} \mid s_{t}\right)$.

\section{The model's general equilibrium}

The decision-making of workers in competitive equilibrium is summarized by the outcome of the following dynamic programming problem:

$$
V[b(\lambda) ; s]=\max _{c, \dot{b}^{\prime}\left(\dot{\lambda}^{\prime}\right), l}\left\{U(c, 1-l)+\mathrm{e}^{-v(c, 1-l)} \int V\left[b^{\prime}\left(\lambda^{\prime}\right) ; s^{\prime}\right] \mathrm{d} S\left(s^{\prime} \mid s\right)\right\},
$$

subject to

$$
c+\int p\left(\lambda^{\prime}\right) b^{\prime}\left(\lambda^{\prime}\right) \mathrm{d} \lambda^{\prime} \leq w l+b(\lambda)
$$

where $w$ is the spot market real wage rate. [To ease the burden on notation, time subscripts have been dropped in the standard fashion, and the function $v(U(c, 1-l))$ has been rewritten more compactly as $v(c, 1-l)$.]

The solution to the above programming problem is characterized by the two efficiency conditions shown below - in addition to (7):

$$
\begin{aligned}
& p\left(\lambda^{\prime}\right)\left[U_{1}(c, 1-l)-v_{1}(c, 1-l) \mathrm{e}^{-v(c, 1-l)} \int V\left[b^{\prime}\left(\lambda^{\prime}\right) ; s^{\prime}\right] \mathrm{d} S\left(s^{\prime} \mid s\right)\right] \\
& =\mathrm{e}^{v(c, 1} l^{\prime}\left[U_{1}\left(c^{\prime}, 1-l^{\prime}\right)-v_{1}\left(c^{\prime}, 1-l^{\prime}\right) \mathrm{e}^{v\left(c^{\prime}, 1-l^{\prime}\right)} \int V\left[b^{\prime \prime}\left(\lambda^{\prime \prime}\right) ; s^{\prime \prime}\right]\right. \\
& \left.\quad \times \mathrm{d} S\left(s^{\prime \prime} \mid s^{\prime}\right)\right] \Lambda\left(\lambda^{\prime} \mid s\right), \quad \text { for all } \lambda^{\prime}, \\
& w U_{1}(c, 1-l)=U_{2}(c, 1-l) .
\end{aligned}
$$

Eq. (8) is the optimality condition governing the worker's purchases of contingent claims. The left-hand side of this expression illustrates the marginal cost of purchasing a contingent claim today which pays one unit of consumption tomorrow if the state of technology then is $\lambda^{\prime}$. Such a claim costs $p\left(\lambda^{\prime}\right)$ units of current consumption. This leads to losses of, first, $U_{1}(c, 1-l)$ in current utility and, second, $-v_{1}(c, 1-l) \mathrm{e}^{-v(c, 1-l)} \int V\left[b^{\prime}\left(\lambda^{\prime}\right) ; s^{\prime}\right] \mathrm{d} S\left(s^{\prime} \mid s\right)$ in discounted future expected utility, the latter effect due to the increase in the agent's subjective 
discount factor used to weight future expected lifetime utility (where the latter is a negative number). The right-hand side of (8) represents the marginal benefit of purchasing today a claim to a unit of consumption next period contingent on the occurrence of $\lambda^{\prime}$. Conditional upon this state occurring, the worker would realize next period a gain in expected lifetime utility of $\left[U_{1}\left(c^{\prime}, 1-l^{\prime}\right)\right.$ $\left.-v_{1}\left(c^{\prime}, 1-l^{\prime}\right) \mathrm{e}^{-v\left(c^{\prime}, 1-l^{\prime}\right)} \int V\left[b^{\prime \prime}\left(\lambda^{\prime \prime}\right) ; s^{\prime \prime}\right] \mathrm{d} S\left(s^{\prime \prime} \mid s^{\prime}\right)\right]$. The discounted, unconditional expected value of this gain is given by the right side of (8), where again $\Lambda\left(\lambda^{\prime} \mid s\right)$ is the marginal density function for $\lambda^{\prime}$, conditional on $s$, that is associated with the transition function $S\left(s^{\prime} \mid s\right)$. Finally, Eq. (9) characterizes the worker's allocation of labor effort; it sets the marginal benefit from working equal to the marginal disutility of labor.

Similarly, the decision-making of entrepreneurs in competitive equilibrium is described by the solution to the dynamic programming problem shown below: ${ }^{7}$

$$
J[a(\lambda), k ; s]=\max _{x, k^{\prime}, \hat{a}^{\prime}\left(\hat{\lambda}^{\prime}\right), l, h}\left\{Z(x, 1-h)+\mathrm{e}^{-\phi(x, 1-h)} \int J\left[a^{\prime}\left(\lambda^{\prime}\right), k^{\prime} ; s^{\prime}\right] \mathrm{d} S\left(s^{\prime} \mid s\right)\right\},
$$

subject to

$$
x+k^{\prime}+\int p\left(\lambda^{\prime}\right) a^{\prime}\left(\lambda^{\prime}\right) \mathrm{d} \lambda^{\prime}+w n l \leq F(k, n l, h ; \lambda)+(1-\delta) k+a(\lambda)
$$

The upshot of the implied maximization routine is the following set of efficiency conditions:

$$
\begin{aligned}
& {\left[Z_{1}(x, 1-h)-\phi_{1}(x, 1-h) \mathrm{e}^{-\phi(x, 1-h)} \int J\left[a^{\prime}\left(\lambda^{\prime}\right), k^{\prime} ; s^{\prime}\right] \mathrm{d} S\left(s^{\prime} \mid s\right)\right]} \\
& =\mathrm{e}^{-\phi(x, 1-h)} \int\left[Z_{1}\left(x^{\prime}, 1-h^{\prime}\right)-\phi_{1}\left(x^{\prime}, 1-h^{\prime}\right) \mathrm{e}^{-\phi\left(x^{\prime}, 1-h^{\prime}\right)} \int J\left[a^{\prime \prime}\left(\lambda^{\prime \prime}\right), k^{\prime \prime} ; s^{\prime \prime}\right]\right. \\
& \left.\quad \times \mathrm{d} S\left(s^{\prime \prime} \mid s^{\prime}\right)\right]\left[F_{1}\left(k^{\prime}, n l^{\prime}, h^{\prime} ; \lambda^{\prime}\right)+(1-\delta)\right] \mathrm{d} S\left(s^{\prime} \mid s\right),
\end{aligned}
$$

\footnotetext{
${ }^{7}$ Again, to ease on notation, let the function $\phi(Z(x, 1-h))$ be expressed more compactly as $\phi(x, 1-h)$.
} 


$$
\begin{aligned}
& p\left(\lambda^{\prime}\right)\left[Z_{1}(x, 1-h)-\phi_{1}(x, 1-h) \mathrm{e}^{-\phi(x, 1-h)} \int J\left[a^{\prime}\left(\lambda^{\prime}\right), k^{\prime} ; s^{\prime}\right] \mathrm{d} S\left(s^{\prime} \mid s\right)\right] \\
& =\mathrm{e}^{-\phi(x, 1-h)}\left[Z_{1}\left(x^{\prime}, 1-h^{\prime}\right)-\phi_{1}\left(x^{\prime}, 1-h^{\prime}\right) \mathrm{e}^{-\phi\left(x^{\prime}, 1-h^{\prime}\right)} \int J\left[a^{\prime \prime}\left(\lambda^{\prime \prime}\right), k^{\prime \prime} ; s^{\prime \prime}\right]\right. \\
& \left.\quad \times \mathrm{d} S\left(s^{\prime \prime} \mid s^{\prime}\right)\right] \Lambda\left(\lambda^{\prime} \mid s\right), \text { for all } \lambda^{\prime}, \\
& F_{2}(k, n l, h ; \lambda)=w, \\
& F_{3}(k, n l, h ; \lambda) Z_{1}(x, 1-h)=Z_{2}(x, 1-h) .
\end{aligned}
$$

The first equation, (12), characterizes optimal capital accumulation in the model. The next expression is the entrepreneur's efficiency condition governing purchases of contingent claims. The optimal employment of workers is regulated by (14). Finally, (15) specifies the amount of labor effort the entrepreneur will expend.

In the model's general equilibrium, both the markets for goods and contingent claims must clear. This necessitates that the two conditions below must hold:

$$
n c+x+k^{\prime}=F(k, n l, h ; \lambda)+(1-\delta) k
$$

and

$$
a^{\prime}\left(\lambda^{\prime}\right)+n b^{\prime}\left(\lambda^{\prime}\right)=0, \text { for all } \lambda^{\prime}
$$

The formal characterization of the model's general equilibrium is now almost complete.

Note that Eqs. (16) and (17) can be used to solve out for $x, x^{\prime}, a^{\prime}, a^{\prime \prime}$ in Eqs. (10), (12), (13), and (15). Similarly, (7) can be used to eliminate $c$ and $c^{\prime}$ in (6), (8), and (9). Also, (14) allows for $w$ to be substituted out for in (9). Finally, observe that Eqs. (8) and (13) hold for each $\lambda^{\prime}$ in the set $L^{\prime}=\left\{\lambda^{1^{\prime}}, \lambda^{2^{\prime}}, \ldots, \lambda^{q^{\prime}}\right\}$. Having done this, it is easy to deduce that (6), (8), (9), (10), (12), (13), and (15) represent a system of functional equations implicitly defining solutions for the equilibrium value functions $V$ and $J$, the policy rules $\vec{b}^{\prime}\left(\vec{\lambda}^{\prime}\right), l, k^{\prime}$, and $h$, and price functions $\vec{p}\left(\dot{\lambda}^{\prime}\right) \equiv\left[p\left(\lambda^{1^{\prime}}\right), \ldots, p^{\prime}\left(\lambda^{q^{\prime}}\right)\right]$. Denote the solutions for the policy rules and price functions by $\vec{b}^{\prime}\left(\vec{\lambda}^{\prime}\right)=\vec{b}^{\prime}(s), l=l(s), k^{\prime}=k^{\prime}(s), h=h(s)$, and $\vec{p}\left(\vec{\lambda}^{\prime}\right)=\vec{p}(s)$. Let the $i$ th components of the vector functions $\vec{b}^{\prime}(s)$ and $\vec{p}(s)$ be represented by $b^{\prime}\left(\lambda^{i^{\prime}} ; s\right)$ and $p\left(\lambda^{i^{\prime}} ; s\right)$. 
The state variable, $s$, remains to be specified. From the analysis above it is probably clear that $s$ is given by the triplet $[b(\lambda), k, \lambda]$, representing the distribution of wealth between workers and entrepreneurs, the capital stock, and the state of technology. Given the current-state-of-the-world, $s$, next period's state, $s^{\prime}$, is given by $s^{\prime}=\left[b^{\prime}\left(\lambda^{\prime} ; s\right), k^{\prime}(s), \lambda^{\prime}\right]$. The conditional distribution governing next period's state, $s^{\prime}$, can easily be seen to be

$$
\begin{aligned}
S\left(s^{\prime} \mid s\right) & =\operatorname{prob}\left[\tilde{b}^{\prime}\left(\tilde{\lambda}^{\prime} ; s\right) \leq b^{\prime}, \tilde{k}^{\prime}(s) \leq k^{\prime}, \tilde{\lambda}^{\prime} \leq \lambda^{\prime} \mid \tilde{b}(\tilde{\lambda})=b, \tilde{k}=k, \tilde{\lambda}=\hat{\lambda}\right] \\
& =\int^{\lambda^{\prime} / \lambda^{\rho}} I\left[\tilde{b}^{\prime}\left(\hat{\lambda}^{\rho} \tilde{\varepsilon}^{\prime} ; s\right)-b^{\prime}\right] I\left[\tilde{k}^{\prime}(s)-k^{\prime}\right] \operatorname{dE}\left(\tilde{\varepsilon}^{\prime}\right),
\end{aligned}
$$

where $I(z)=1$ if $z \leq 0$ and $I(z)=0$ if $z>0$.

\section{Market structure}

Many different structures for financial markets are consistent with the real allocations generated by the competitive equilibrium modeled above. To begin with, note that the assumption that workers cannot hold physical capital is innocuous. A unit of capital purchased today pays off the return $\left[F_{1}\left(k^{\prime}(s), n l\left(s^{\prime}\right), h\left(s^{\prime}\right) ; \lambda^{\prime}\right)+(1-\delta)\right]$ next period. While prohibited from holding physical capital, a worker could buy a portfolio of contingent claims mimicking this return. This portfolio would cost $\int p\left(\lambda^{\prime} ; s\right)\left[F_{1}\left(k^{\prime}(s), n l\left(s^{\prime}\right), h\left(s^{\prime}\right) ; \lambda^{\prime}\right)+\right.$ $(1-\delta)] \mathrm{d} \lambda^{\prime}$ units of current consumption. Using (12) and (13) it is easy to see that $\int p\left(\lambda^{\prime} ; s\right)\left[F_{1}\left(k^{\prime}(s), n l\left(s^{\prime}\right), h\left(s^{\prime}\right) ; \lambda^{\prime}\right)+(1-\delta)\right] \mathrm{d} \lambda^{\prime}=1$, implying that in a competitive equilibrium this portfolio costs the same as a unit of capital.

Clearly, whether or not workers and entrepreneurs trade contingent claims on a scparatc financial market or instead do so through the structure of a firm should be immaterial for the model's real allocations. It will, however, be material for the measurement of prices such as wages and the return to capital. Now, envision an environment where the contingent claims desired by workers are loaded directly into the wage packages paid by firms. Denote the measured real wage in this setting by $\hat{w}$. From the worker's budget constraint, (7), it is apparent that measured labor income in this economy, $\hat{w} l$, would read as

$$
\hat{w}(s) l(s)=w(s) l(s)+b(\lambda)-\int p\left(\hat{\lambda}^{\prime} ; s\right) b^{\prime}\left(\lambda^{\prime} ; s\right) \mathrm{d} \lambda^{\prime}
$$

with the measured real wage being given by

$$
\hat{w}(s)=w(s)+\frac{b(\lambda)-\int p\left(\lambda^{\prime} ; s\right) b^{\prime}\left(\lambda^{\prime} ; s\right) \mathrm{d} \lambda^{\prime}}{l(s)} .
$$


Additionally, one could assume that not all workers are covered by the above labor contract. Specifically, assume that the fraction $u$ is. Measured labor income would now be $[u \hat{w}(s)+(1-u) w(s)] l(s)$.

Alternatively, one can imagine a setting where workers channel their savings through a bond market to entrepreneurs who use the funds to accumulate physical capital. Insurance against cyclical fluctuations could be provided by firms for workers as part of their wage package. Specifically, let the market price today of a bond paying back one unit of output next period be $1 / r(s)$; arbitrage dictates that the gross interest rate, $r(s)$, will be given by $1 / r(s)=\int p\left(\lambda^{\prime} ; s\right) \mathrm{d} \lambda^{\prime}$. In the general equilibrium modeled above, workers expect to have $\bar{b}^{\prime}(s) \equiv \int b^{\prime}\left(\lambda^{\rho} \varepsilon^{\prime} ; s\right) \mathrm{dE}\left(\varepsilon^{\prime}\right)$ units of wealth next period. Now, suppose that workers save through the bond market to attain this target level of wealth. The worker's budget constraint, (7), can accordingly be rewritten as

$$
\begin{aligned}
& c(s)+\int p\left(\lambda^{\prime} ; s\right) \bar{b}^{\prime}(s) \mathrm{d} \lambda^{\prime}+\int p\left(\lambda^{\prime} ; s\right)\left[b^{\prime}\left(\lambda^{\prime} ; s\right)-\bar{b}^{\prime}(s)\right] \mathrm{d} \lambda^{\prime} \\
& \leq w(s) l(s)+\bar{b}+[b(\lambda)-\bar{b}] .
\end{aligned}
$$

Here, the term $\int p\left(\lambda^{\prime} ; s\right) \bar{b}^{\prime}(s) \mathrm{d} \lambda^{\prime}$ represents the worker's savings in bonds which will yield the return $\bar{b}^{\prime}(s)$ in principal and interest next period, while $\int p\left(\lambda^{\prime} ; s\right)\left[b^{\prime}\left(\lambda^{\prime} ; s\right)-\bar{b}^{\prime}(s)\right] \mathrm{d} \lambda^{\prime}$ is the amount paid in premiums for insurance paying off $\left[b^{\prime}\left(\lambda^{\prime} ; s\right)-\bar{b}^{\prime}(s)\right]$ units of output next period contingent on the event $\lambda^{\prime}$ occurring. If firms provide the insurance against cyclical fluctuations as part of the worker's wage package, then measured labor income in the economy, $\tilde{w} l$, would be given by

$$
\tilde{w}(s) l(s)=w(s) l(s)+[b(\lambda)-\bar{b}]-\int p\left(\lambda^{\prime} ; s\right)\left[b^{\prime}\left(\lambda^{\prime} ; s\right)-\bar{b}^{\prime}(s)\right] \mathrm{d} \lambda^{\prime},
$$

with the measured real wage, $\tilde{w}$, being correspondingly defined as

$$
\tilde{w}(s)=w(s)+\frac{[b(\lambda)-\bar{b}]-\int p\left(\lambda^{\prime} ; s\right)\left[b^{\prime}\left(\lambda^{\prime} ; s\right)-\bar{b}^{\prime}(s)\right] \mathrm{d} \lambda^{\prime}}{l(s)} .
$$

\section{Model parameterization and calibration}

To begin with, let tastes and technology be specified in the following way:

$$
U(c, 1-l)=\frac{\left[c^{\omega}(1-l)^{1-\omega}\right]^{1-\gamma}}{1-\gamma}, \quad 0 \leq \omega \leq 1, \quad \gamma>1,
$$




$$
\begin{aligned}
& Z(x, 1-h)=\frac{\left[x^{\theta}(1-h)^{1-\theta}\right]^{1-\varphi}}{1-\varphi}, \quad 0 \leq \theta \leq 1, \quad \varphi>1 \\
& v(c, 1-l)=\ln \left[1+\eta c^{\omega}(1-l)^{1-\omega}\right], \quad \eta \geq 0 \\
& \phi(x, 1-h)=\ln \left[1+\mu x^{\theta}(1-h)^{1-\theta}\right], \quad \mu \geq 0 \\
& F(k, n l, h ; \lambda)=\lambda\left\{\alpha k^{1-\zeta}+(1-\alpha)\left[l(n l)^{1-\kappa}+(1-l) h^{1-\kappa}\right]^{(1-\zeta) /(1-\kappa)\}}\right\}^{1 /(1-\zeta)}, \\
& \quad 0 \leq \alpha, l \leq 1, \quad \kappa, \zeta \geq 0 .
\end{aligned}
$$

Observe that the functions $U$ and $Z$ are negative and have the property that $\ln (-U)$ and $\ln (-Z)$ are strictly convex.

Notice that Eqs. (25) and (26) imply

$$
\mathrm{c}^{-v(c, 1-l)}=\frac{1}{1+\eta c^{\omega}(1-l)^{1-\omega}}
$$

and

$$
\mathrm{e}^{-\phi(x, 1-h)}=\frac{1}{1+\mu x^{\theta}(1-h)^{1-\theta}} .
$$

Consequently, constant discount rates are a special case in which $\eta=\mu=0 .^{8}$ Recalling that the time-varying discount rate reflects an impatience effect, it can be seen that the larger is $c^{\omega}(1-l)^{1-\omega}$, the smaller is $\mathrm{e}^{-v(c, 1-l)}$, and so workers will in fact discount future utility more heavily. Similarly so for the entrepreneur.

The stochastic process (2) governing the technology shock will now be parameterized. In particular, suppose that the $\lambda$-process's innovation, $\varepsilon$, is described by a two-state Markov process. Specifically, $\varepsilon$ is assumed to have a value lying in the time-invariant two-point set

$$
A=\left\{\mathrm{e}^{\xi}, \mathrm{e}^{-\xi}\right\}
$$

with the following probabilities:

$$
\operatorname{prob}\left\{\varepsilon=\mathrm{e}^{\xi}\right\}=\frac{1}{2} \text { and } \operatorname{prob}\left\{\varepsilon=\mathrm{e}^{-\xi}\right\}=\frac{1}{2} \text {. }
$$

\footnotetext{
${ }^{8}$ Given the current forms of (28) and (29), the entrepreneurs' and workers' discount factors converge to unity as $\eta$ and $\mu$ approach zero. Clearly, any values for the limiting discount factors can be obtained by setting the numerators of these expressions to the desired numbers.
} 
With this parameterization (the logarithm of) the $\lambda$-process has a standard deviation given by $\sigma=\xi / \sqrt{\left(1-\rho^{2}\right)}$ and a serial correlation coefficient of $\rho$.

In order to simulate the model, values must be assigned to the parameters shown below:

\begin{tabular}{ll}
\hline Utility - Workers: & $\eta, \omega, \gamma$ \\
\hline Utility - Entrepreneurs: & $\mu, \theta, \varphi$ \\
\hline Technology: & $\alpha, \kappa, l, \zeta, \delta, n, \sigma, \rho$ \\
\hline
\end{tabular}

So as to impose some discipline on the simulation experiments being conducted, the calibration procedure advanced by Kydland and Prescott (1982) is adopted. In line with this approach as many model parameter values as possible are set in advance based upon either (a) a priori information about their magnitudes or (b) so that in the model's deterministic steady-state, values for various endogenous variables assume their average values for the postwar U.S. economy, based upon quarterly data for the 1954-1989 sample period.

To begin with, in the benchmark economy production is Cobb-Douglas in capital and aggregate labor effort; that is, $\zeta$ equals one. Capital's share of income, or $\alpha$, was set to 0.36 , its average quarterly value over the 1954-1989 sample period. The depreciation rate, $\delta$, was chosen to be 0.025 , the value used by Kydland and Prescott (1982). The parameters $\kappa$ and $t$ specify how the two types of labor input are aggregated in the production function. They govern the relative value of these inputs in production. In the U.S., the top one percent earn about 8.2 times that of the bottom 99 percent. This figure is calculated by estimating the U.S. income distribution for the years 1979 to 1990 - see Appendix B. This implies that the top one percent are paid a wage rate 8.2 times higher than that earned by the bottom 99 percent, assuming individuals in both groups work about the same number of hours. Unfortunately, there is no other independent evidence available to guide the joint choice of $\kappa$ and $l$ so that these two parameter values have been picked on the basis of one restriction. Thus, the elasticity of substitution between workers and entrepreneurs, $1 / \kappa$, was arbitrarily set to 2.0 implying that $\kappa=0.5$. Given this magnitude for $\kappa$, the value for $l$ was chosen such that, in the steady state, the representative entrepreneur earns 8.2 times that of the average worker; this resulted in $t$ equaling 0.5482 . The parameters $\sigma$ and $\rho$ specifying the $\lambda$-process's standard deviation and autocorrelation can be determined by computing the Solow residuals for an aggregate production function from the U.S. data. Using quarterly data for the postwar period, Prescott (1986) reports values for $\sigma$ and $\rho$ of 0.0244 and 0.95 , respectively. 
These numbers were used here to calibrate the process governing technical changes.

Next, the parameters $\omega, \eta, \mu$, and $\theta$ were chosen so that the model's deterministic steady state satisfies four restrictions. The first two restrictions constrain the ratio of working to total hours for workers and entrepreneurs to be 0.24 . This number corresponds to the average ratio of hours worked to total nonsleeping hours of the working age population observed in the U.S. data. The third restriction sets the steady-state real interest rate (at the quarterly level) to be one percent. Finally, the last restriction specifies that the wcalthiest one percent of the population holds 25 percent of aggregate wealth. This number conforms with statistics on this century's wealth distribution for the U.S. - see Wolff and Marley (1989). If entrepreneurs are viewed as comprising the upper one percent of the wealth distribution, then $n$ should equal 99. Again, the values for $\omega, \eta, \mu$, and $\theta$ were picked so that the model's steady state satisfied these four restrictions.

Specifically, given the current parameterization for tastes and technology the steady-state analogues to Eqs. (7), (8) (9), (12), (13), (15), and (16) are

$$
\begin{aligned}
& p=\frac{1}{1+\eta c^{\omega}(1-l)^{1-\omega}}, \\
& (1-\alpha) k^{\alpha}\left[l(n l)^{1-\kappa}+(1-l) h^{1-\kappa}\right]^{(\kappa-\alpha) /(1-\kappa)} l(n l)^{-\kappa} \omega(1-l)=(1-\omega) c \\
& c+[p-1] b=(1-\alpha) k^{\alpha}\left[l(n l)^{1-\kappa}+(1-l) h^{1-\kappa}\right]^{(\kappa-\alpha) /(1-\kappa)} l n^{-\kappa} l^{1-\kappa} \\
& 1=\frac{\alpha k^{\alpha-1}\left[l(n l)^{1-\kappa}+(1-l) h^{1-\kappa}\right]^{(1-\alpha) /(1-\kappa)}+(1-\delta)}{1+\mu x^{\theta}(1-h)^{1-\theta}} \\
& p=\frac{1}{1+\mu x^{\theta}(1-h)^{1-\theta}}, \\
& (1-\alpha) k^{\alpha}\left[l(n l)^{1-\kappa}+(1-\imath) h^{1-\kappa}\right]^{(\kappa-\alpha) /(1-\kappa)}(1-\imath) h^{-\kappa} \theta(1-h)=(1-\theta) x \\
& n c+x+\delta k=k^{\alpha}\left[l(n l)^{1-\kappa}+(1-\imath) h^{1-\kappa}\right]^{(1-\alpha) /(1-\kappa)} .
\end{aligned}
$$

The four restrictions from the long-run data discussed above imply

$$
\begin{aligned}
& l=0.24, \\
& h=0.24,
\end{aligned}
$$




$$
\begin{aligned}
& p=1 / 1.01, \\
& k-99 p b=0.25 k .
\end{aligned}
$$

Given values for $\alpha$ and $\delta$ this system of eleven equations in eleven unknowns can be thought of as determining a solution for the eleven unknowns $c, l, b, x, k, h, p, \omega, \eta, \mu$, and $\theta$. The parameter values obtained for $\omega, \eta, \mu$, and $\theta$ are $0.2632,0.0187,0.0092$, and $0.3256 .{ }^{9}$

Two parameters remain to be specified: the coefficients of relative risk aversion, $\gamma$ and $\varphi$, for workers and entrepreneurs. The value of this parameter is somewhat controversial, but Prescott (1986) suggests that the weight of the evidence places it not too far from 1.0. In line with this, a value of 1.5 was picked for both entrepreneurs and workers.

\section{Findings}

\subsection{Aggregate fluctuations}

The model's implications for the cyclical pattern of comovements among macroaggregates will now be investigated. The variables targeted for study are output, consumption, investment, hours, productivity, labor's share of income, and wages. Table 1 presents some stylized facts that characterize U.S. business cycles for the 1954-1989 sample period. The statistics reported are based on quarterly data which has been detrended using the Hodrick-Prescott $(\mathrm{H}-\mathrm{P})$ filter. The corresponding statistics for the model are shown in Table 2. The model's statistics were constructed in the following manner: First, piecewise linear equilibrium decision rules for both the entrepreneur and worker were

\footnotetext{
${ }^{9} \mathrm{~A}$ few words on the steady-state distribution of wealth between workers and entrepreneurs might be in order. Note that given values for the parameters $\eta, \omega, \gamma, \mu, \theta, \varphi, \alpha, \kappa, l, \delta$, and $n$, the system of seven equations (30) to (36) determines a solution for the seven unknowns $c, x, k, l, h, p$, and $b$. Now, instead, consider a version of the model where agents have a constant discount factor, $\beta$. In this case (33) reads $1 / \beta=\alpha \kappa^{\alpha-1}\left[\imath(n l)^{1-x}+(1-\imath) h^{1-\kappa}\right]^{(1-\alpha) /(1-\kappa)}+1-\delta$. Eqs. (30) and (34) both collapse to $p=\beta$ so that one of them, say (30), can be discarded. The rest of the system remains the same. Here the system of six equations (31) to (36) determine a solution for the six variables $c, x, k, l, h$, and $p$, given a value for $b$. Thus, it is easy to see that when discount factors are constant, the deterministic version of the method does not possess a unique, invariant steady-state distribution of wealth across entrepreneurs and workers. The long-run distribution of income will depend upon the initial distribution of wealth. The endogenous discount factor allows convergence to a unique steady-state wealth distribution in the following way: When an agent has a level of wealth below (above) his steady-state level, his discount factor is high (low). This encourages (discourages) savings so that his asset holdings increase (decrease) over time to their long-run level. This lets the model possess a stable long-run distribution of wealth across agents, as is observed in the U.S. data.
} 
Table 1

Quarterly U.S. data, 1954-1989

\begin{tabular}{lllc}
\hline & $\begin{array}{l}\text { Standard } \\
\text { deviation }\end{array}$ & $\begin{array}{l}\text { First-order } \\
\text { autocorrelation }\end{array}$ & $\begin{array}{c}\text { Correlation } \\
\text { with output }\end{array}$ \\
\hline Output & 1.70 & 0.85 & 1.00 \\
Consumption & 0.85 & 0.84 & 0.75 \\
Investment & 8.28 & 0.82 & 0.90 \\
Hours & 1.96 & 0.89 & 0.89 \\
Productivity & 0.90 & 0.71 & -0.05 \\
Labor's share of income & 0.80 & 0.71 & -0.35 \\
Real wage & 0.74 & 0.73 & -0.44 \\
\hline
\end{tabular}

The data for all the series reported was logged and detrended using the Hodrick-Prescott filter. The original data used was expressed in 1982 dollars and deflated by the $16+$ population. GNP, the GNP deflator, consumption (nondurable goods plus services), and gross investment were taken from the national income accounts. Labor's share of income was computed by dividing the compensation of employees by GNP, again both series being taken from the national income accounts. Hours corresponds to hours of all employees in the business sector (Citibase variable $L B H E$ ). Productivity is defined as output divided by hours, while the real wage was computed by dividing the compensation of employees by hours. The data series were taken from the Fame Economic Database of the Board of Governors of the Federal Reserve System.

Table 2

Benchmark model

\begin{tabular}{|c|c|c|c|c|}
\hline \multirow{2}{*}{$\cdots$} & \multirow{2}{*}{ - - } & \multirow{2}{*}{$\begin{array}{l}\text { Standard } \\
\text { deviation }\end{array}$} & \multirow{2}{*}{$\begin{array}{l}\text { First-order } \\
\text { autocorrelation }\end{array}$} & \multirow{2}{*}{$\begin{array}{l}\text { Correlation } \\
\text { with output }\end{array}$} \\
\hline & & & & \\
\hline Output & & 1.60 & 0.69 & 1.00 \\
\hline Consumption & & 0.41 & 0.85 & 0.76 \\
\hline Investment & & 5.39 & 0.67 & 0.99 \\
\hline Hours & & 0.99 & 0.67 & 0.98 \\
\hline Productivity & & 0.66 & 0.74 & 0.95 \\
\hline \multicolumn{2}{|l|}{ Labor's share of income $\hat{w} l / y$} & 1.31 & 0.67 & -0.98 \\
\hline & $1 / y$ & 1.63 & -0.09 & -0.43 \\
\hline \multirow[t]{2}{*}{ Real wage } & & 0.81 & 0.71 & -0.81 \\
\hline & $i$ & 1.58 & 0.10 & -0.04 \\
\hline
\end{tabular}

computed using the algorithm described in Appendix C. Next, 50 artificial samples of 144 observations each (the number of quarters in the 1954-1989 sample period) were generated by simulating these decision rules. The data collected from each sample was then detrended using the H-P filter. Finally, these sample moments were averaged over the 50 simulations undertaken.

A loose indication of the model's ability to mimic the observed pattern of postwar U.S. business cycle fluctuations can be obtained by comparing Tables 1 and 2 . It should be said, however, that it would be unreasonable to place high 
expectations on such a patently simplistic abstraction. The first thing to note is that in the model, macroaggregates tend to vary too little. This is fairly typical of real business cycle models that calibrate the technology shock to the observed sample moments for Solow residuals. Clearly, there have been factors other than technology shocks that have affected macroaggregates in the postwar period. In the U.S. data, investment is much more volatile than output, and consumption much less so. The model mimics this feature. Another feature of the data is that investment is more highly correlated with output than is consumption. The model shares this feature too. ${ }^{10}$

Turning now to the behavior of labor income over the business cycle, it can be seen in Table 2 that both measures of labor's share of income move countercyclically, i.e., are negatively correlated with output. The first measure, based on Eq. (19), includes workers' savings and tends to be far too countercyclical. Here, the correlation between labor's share of income and output is -0.98 as opposed to the value of -0.35 that characterizes the data. The second measure is constructed using (21) and attempts to net out workers' savings. Now, the correlation between labor's share of income and output drops to -0.43 , which is more in line with the evidence. Not surprisingly, then, the first measure of labor income implies a more countercyclical real wage than the second one does; the correlations with output are -0.81 and -0.04 , respectively. If one takes the commonly held position that the real wage exhibits no strong cyclical pattern, then the second measure also performs better in this dimension. It may be the case that not all workers in the economy are covered by implicit labor contracts. Suppose, for example, that half are, with the rest selling their labor services on a spot market. Then the correlations between the real wage and output rise to -0.16 and 0.31 , with those between labor's share of income and output remaining the same. ${ }^{11}$

In the U.S. data, labor's share of income tends to lag the business cycle. GNP is negatively correlated with leaded values of labor's share of income (lsi) and tends to be positively associated with lagged ones; see Table 3. [Similar findings are reported in Bils and Cho (1992), Costello and Praschnik (1992), and

\footnotetext{
${ }^{10}$ Some limited experimentation suggests that the value chosen for Greek kappa does not have a significant effect on the results obtained. For instance, a change in Greek kappa from 0.50 to 1.33 never leads to a difference in the reported statistics of more than 0.05 in absolute value with two exceptions: the percentage variability in the second measure of labor's share of income and the real wage rise from 1.63 to 1.81 and 1.58 to 1.74 , respectively.

${ }^{11}$ The correlations between the first and second measures of the real wage on the one hand, and hours worked on the other are -0.60 and 0.14 . Thus, the second measure of the real wage accords better with conventional wisdom that there is no strong empirical relationship between real wages and hours worked.
} 
Table 3

Labor's share of income real output correlations

\begin{tabular}{lllllllllll}
\hline & $\operatorname{Corr}\left(l s i_{+j}, y_{t}\right)$ \\
\cline { 2 - 9 } & $j=-4$ & $j=-3$ & $j=-2$ & $j=-1$ & $j=0$ & $j=+1$ & $j=+2$ & $j=+3$ & $j=+4$ \\
\hline U.S. data & -0.34 & -0.42 & -0.49 & -0.44 & -0.35 & -0.01 & 0.26 & 0.44 & 0.49 \\
Model & -0.15 & -0.22 & -0.28 & -0.34 & -0.44 & 0.34 & 0.28 & 0.24 & 0.28 \\
\hline
\end{tabular}

Kydland and Prescott (1990).] Somewhat surprisingly, the model mimics this sign pattern quite well. ${ }^{12}$

In at least one respect the implicit labor contracting story does not perform that well. For instance, by either measure labor's share of income and the real wage are a bit too volatile. To understand why, note that implicit labor contracts are designed not to stabilize the real wage paid to workers but instead to smooth out fluctuations in workers' utility. Now suppose that labor income was held constant over the business cycle. Then labor's share of income would have the same percentage variability as output ( 1.60 in the model) while the real wage would vary as much as hours (0.99). ${ }^{13}$ Additionally, when the second measure is used for labor income, the real wage rate and labor's share of income display no serial correlation, in contrast with the data. Here labor income has a large insurancc component in it, which by its very nature varies unpredictably.

From the long-run data, it is difficult to discern whether labor's share of income has risen over time - see Romer (1989). ${ }^{14}$ If it has, then the long-run data would suggest that a CES production function with an elasticity of substitution between labor and capital that is less than one, is a better choice than a Cobb-Douglas one. Let the aggregate production function be a CES with an

\footnotetext{
${ }^{12}$ For the eight OECD countries for which data of labor's share of income could be collected, it also transpires that $\operatorname{corr}\left(l s i_{t+j}, G N P_{t}\right)$ is generally increasing in $j$ for $-4 \leq j \leq+4$; see Appendix A. For all countries, GNP displays a negative correlation with lagged values of labor's share of income. As $j$ is increased (for $0 \leq j \leq+4$ ), this correlation monotonically rises in all countries, and eventually becomes positive in each, except Japan. Last, it is hard to detect - not reported in Appendix A - a systematic pattern of correlation between output on the one hand and lagged or leaded real wages on the other. This seems in accord with Blanchard and Fischer's $(1989$, p. 17) view that 'there is very little correlation at any lead or lag between economy-wide real wages and output ....

${ }^{13}$ Let labor income be constant, say at some value $C$. Then labor's share of income would be given by $C / y$ while the real wage would read $C / n l$. Consequently, $\operatorname{var}(\ln (C / y))=\operatorname{var}(\ln (y))$ and $\operatorname{var}(\ln (C / n l))=\operatorname{var}(\ln (n l))$.

${ }^{14}$ As Fig. 1 illustrates, for the postwar U.S. economy, labor's share of income rises or remains constant depending upon the treatment of proprietor's income
} 
Table 4

CES model, $1 / \xi=0.6$

\begin{tabular}{|c|c|c|c|}
\hline & $\begin{array}{l}\text { Standard } \\
\text { deviation }\end{array}$ & $\begin{array}{l}\text { First-order } \\
\text { autocorrelation }\end{array}$ & $\begin{array}{l}\text { Correlation } \\
\text { with output }\end{array}$ \\
\hline Output & 1.36 & 0.69 & 1.00 \\
\hline Consumption & 0.51 & 0.81 & 0.87 \\
\hline Investment & 4.08 & 0.67 & 0.98 \\
\hline Hours & 0.60 & 0.67 & 0.98 \\
\hline Productivity & 0.77 & 0.71 & 0.99 \\
\hline Labor's share of income $\hat{w} l / y$ & 0.95 & 0.67 & -0.96 \\
\hline$\tilde{w} l / y$ & 1.24 & -0.03 & -0.50 \\
\hline \multirow{2}{*}{ Real wage } & 0.39 & 0.84 & -0.39 \\
\hline & 1.15 & 0.26 & 0.13 \\
\hline
\end{tabular}

elasticity of substitution of 0.6 , the value suggested by Lucas $(1990) .{ }^{15}$ Here, in the absence of labor contracting, the model generates a correlation between labor's share of income and output of -0.78 , which is grossly at variance with the data. ${ }^{16}$ The marginal product of labor is strongly procyclical, having a correlation with output of 0.95 . With labor contracting the correlation between labor's share of income and output becomes either -0.96 or -0.50 , depending on the measure used for labor income. The correlations between the real wage and output are -0.39 and 0.13 . Thus, the second measure of labor income performs better again. (The full set of results for the CES economy is reported in Table 4.)

\subsection{Role of the endogenous discount factor}

The role that the endogenous discount factor plays in the model will now be investigated. To do this, the benchmark model will be rerun with less variable

\footnotetext{
${ }^{15}$ The model needs to be recalibrated here so capital's share of income remains at 36 percent. This requires finding a new value for $\alpha$, the weight on capital in the production function. Also, Prescott's (1986) estimates of the time series properties of the Solow residual are predicated upon the assumption that the production function is Cobb-Douglas. Strictly speaking, then, the time series properties of the Solow residual should be reestimated assuming the CES form. The above experiment is intended solely to illustrate the likely impact of decreasing the degree of substitution between capital and labor, ceteris paribus.

${ }^{16}$ Labor's share of income can be written as $w l /(w l+r k)=1 /[1+(r / w)(k / l)]-$ here $l$ represents the aggregate amount of composite labor hired. Let $1 / \zeta$ equal the elasticity of substitution between labor and capital. Then, in response to a technology shock, $\mathrm{d} \ln (r / w) / \mathrm{d} \lambda=-\zeta \mathrm{d} \ln (k / l) / \mathrm{d} \lambda$. Now, suppose that $k / l$ is growing over time. Then labor's share of income will rise secularly provided the elasticity of substitution is less than unity. Contrarily, suppose that $k / l$ declines, as it would in the initial stages of a boom as hours worked expand. Then labor's share of income moves countercyclically if $1 / \zeta<1$.
} 
Table 5

Discount factor experiment

\begin{tabular}{|c|c|c|c|}
\hline & $\begin{array}{l}\text { Standard } \\
\text { deviation }\end{array}$ & $\begin{array}{l}\text { First-order } \\
\text { autocorrelation }\end{array}$ & $\begin{array}{l}\text { Correlation } \\
\text { with output }\end{array}$ \\
\hline Output & 1,47 & 0.69 & 1.00 \\
\hline Consumption & 0.48 & 0.76 & 0.92 \\
\hline Investment & 4.49 & 0.68 & 0.99 \\
\hline Hours & 0.79 & 0.68 & 0.98 \\
\hline Productivity & 0.70 & 0.72 & 0.98 \\
\hline Labor's share of income $\hat{w} l / y$ & 1.04 & 0.68 & -0.98 \\
\hline$\tilde{w} l / y$ & 0.37 & -0.09 & -0.43 \\
\hline \multirow[t]{2}{*}{ Real wage } & 0.47 & 0.75 & -0.72 \\
\hline & 0.68 & 0.82 & 0.78 \\
\hline
\end{tabular}

discount factors. Observe, from expressions (28) and (29), that as $\eta$ and $\mu$ approach zero the model collapses to the constant discount factor case. For the model to keep the same real interest rate in its deterministic steady-state, the numerators of these expressions must also be adjusted simultaneously so that they approach 0.99 . Values of 0.0018 and 0.0009 were chosen for $\eta$ and $\mu$, and the numerators of (28) and (29) were set to $0.991 .{ }^{17}$ This configuration of parameter values preserves the steady-state equilibrium outlined in Section 5.

The results of this simulation exercise are reported in Table 5. Most macroaggregates now become less volatile. For instance, the standard deviations of output, investment, and hours fall from $1.60,5.39$, and 0.99 percent to $1.47,4.49$, and 0.79 . The variability of consumption, however, rises from 0.41 to 0.48 . Also notice that the correlation of consumption with output increases from 0.76 to 0.92 . In short, the effects of this experiment on macroaggregates are similar to a cut in the elasticity of intertemporal substitution in the standard real business cycle model. In other words, endogeneity in the discount factor operates here to increase the amount of intertemporal substitution in the model.

It is easy to understand why endogeneity in the discount factor increases the amount of intertemporal substitution in the model. In Fig. 2 the behavior of the worker's discount factor over the business cycle is plotted for one simulation run. As can be seen, the discount factor moves procyclically. Thus, in times when the technology shock is good, the discount factor is high. This works to entice investment and labor effort in booms and to dissuade consumption. The reverse happens in slumps. It may seem somewhat surprising, though, that the worker's

\footnotetext{
${ }^{17}$ More accurately the numerators of (28) and (29) were set to 0.991 with the values for $\eta$ and $\mu$ of 0.0018 and 0.0009 then being backed out from the calibration procedure that was described in Section 5 .
} 


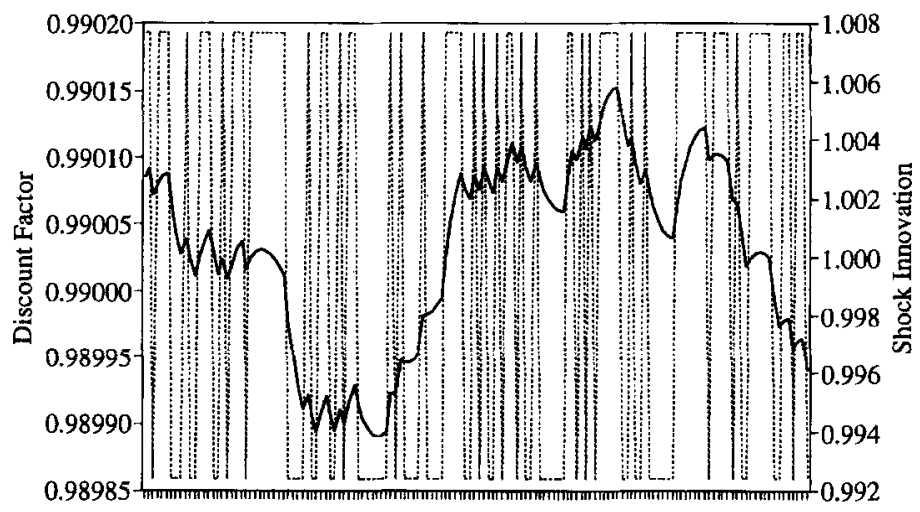

Discount Factor …....... Innovation

Fig. 2. Worker's discount factor.

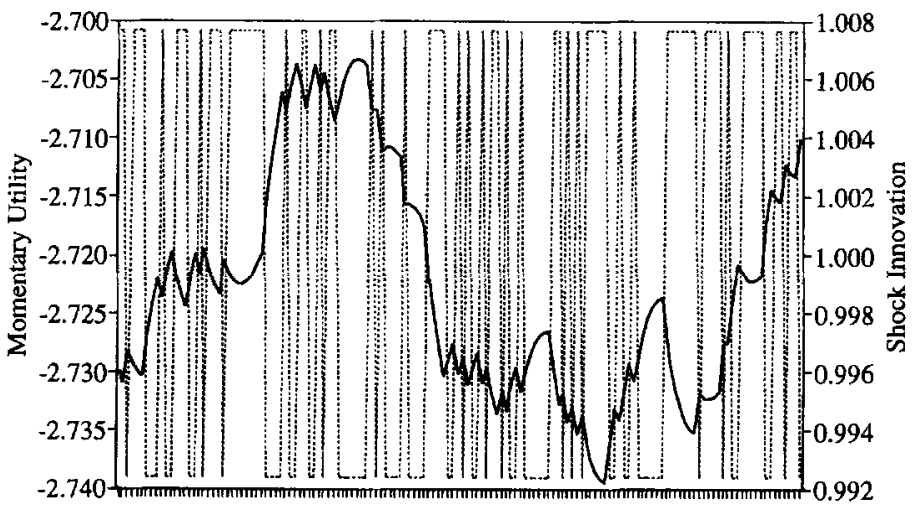

Momentary Utility ……... Innovation

Fig. 3. Worker's momentary utility.

discount factor moves procyclically. Recall that the worker's discount factor is a decreasing function of his momentary utility. Consequently, in order for the worker's discount factor to be procyclical, it must be the case that his momentary utility is countercyclical. Fig. 3 shows the countercyclical movement in momentary utility. In booms the gain in momentary utility from increased consumption is more than offset from the loss due to increased labor effort. Also, 

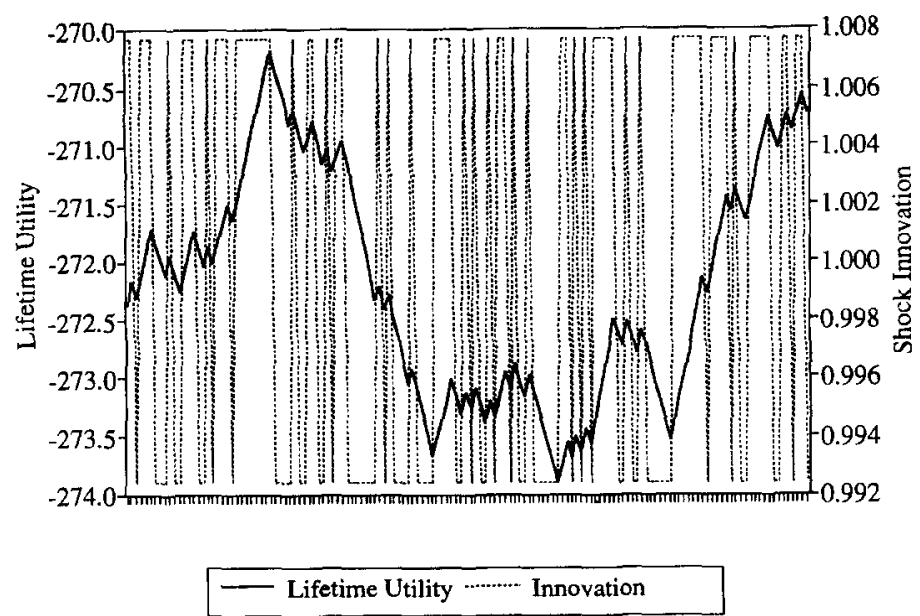

Fig. 4. Worker's lifetime utility.

note in Fig. 4 that the worker's expected lifetime utility (his value function) moves procyclically. Therefore, in booms the worker sacrifices utility today for expected utility tomorrow.

One last observation on the role of the endogenous discount factor. A puzzle in the data is that hours tend to vary twice as much as productivity over the business cycle. As has been noted in Hansen (1985), in real business cycle models hours tend to fluctuate about the same amount as productivity. Hansen resolves this puzzle by introducing an indivisibility into agents' decisions about how much to work. This amplifies the responsiveness of hours worked to a shock in the economy. In fact, in Hansen's model indivisible labor makes hours too variable in the sense that they fluctuate two-and-a-half times as much as productivity. In the benchmark version of the model, the variation in hours is one-and-a-half times that of productivity. Observe that when the degree of endogeneity in the discount factor is cut, this ratio falls to unity. An endogenous discount factor enhances the responsiveness of hours worked to the current state of technology in much the same way as the nonseparability in preferences (for leisure across time) used in Kydland and Prescott (1982). (Tangentially, it is interesting to note that with the CES production function, hours vary only three-quarters as much as productivity.)

The model performs poorly on one dimension here. In particular, the correlation between output and productivity is too high $(0.95$ versus -0.05 in the data). As Christiano and Fichenbaum (1992) note, this is a feature of real business cycle models that rely solely on technology shocks as a source of fluctuations. Given the standard specification of technology, average labor productivity is proportional to the marginal product of labor, with the latter 
moving procyclically by construction. Here, technology shocks can be thought of as affecting the demand side of the labor market. This problem can be resolved by adding other shocks into the model, such as innovations to government spending (Christiano and Eichenbaum, 1992), disturbances to tastes (Bencivenga, 1992), or shifts to a household production function (Benhabib, Rogerson, and Wright, 1991). These shocks operate on the supply side of the labor market. In the standard real business cycle paradigm with such shocks, however, labor's share of income would still be constant over the business cycle. Finally, Hansen and Wright (1992) assess the performance of various real business cycle models along the hours/productivity dimension.

\subsection{Cyclical allocation of risk}

Finally, some observations will be made about the cyclical allocation of risk. ${ }^{18}$ While it is difficult to quantify the amount of cyclical risk that gets shifted in competitive equilibrium from workers to entrepreneurs, an attempt will be made to do so anyway. The analysis on market structure in Section 4 suggests a natural means to measure insurance flows: the difference between spot market labor income and income under labor contracts which incorporate insurance (but not savings). A useful metric of the amount of insurance traded in equilibrium might then be

$$
\int \frac{n l|w(s)-\tilde{w}(s)|}{y(s)} \mathrm{d} S^{*}(s)
$$

where $\tilde{w}(s)$ is the wage rate under the labor contract and $S^{*}(s)$ represents the long-run distribution governing the state variables; i.e., $S^{*}(s)$ solves $S^{*}\left(s^{\prime}\right)=\int S\left(s^{\prime} \mid s\right) \mathrm{d} S^{*}(s)$. This metric can be thought of as measuring the flows of insurance against cyclical risk as a fraction of output.

In much the same way that Solow residuals are calculated, an analogue to (41) can be computed for the U.S. economy. Specifically, taking the stand that the aggregate production function is Cobb-Douglas, the marginal product of labor (or spot market real wage) can be calculated as $w=(1-\alpha) y / l$. For the actual real wage, $\tilde{w}$, the series created by dividing the National Income and Product Account's data on compensation of employees through by a measure of aggregate hours worked was used. The average ratio insurance flows to income [the data analogue to (41)] was about 0.7 percent for the U.S. economy. ${ }^{19}$

\footnotetext{
${ }^{18}$ The exercise conducted is to attempt to quantify the quantity of insurance transacted against aggregate cyclical risk. It ignores idiosyncratic risk associated with firm or industry heterogeneity.

${ }^{19}$ Since Proprietor's Income includes both labor and capital income, it has been netted out of GNP for these calculations.
} 
In the benchmark model, insurance transactions against cyclical risk amount to about 1.0 percent of output, slightly higher than calculated for the U.S. economy. This number is small, but that should not be surprising for three reasons: First, the variability in macroaggregates is small. For example, output and hours have standard deviations of 1.60 and 0.99 percent, while consumption's variability is even smaller, as reflected by its standard deviation of only 0.41 . Second, both sets of agents share the same coefficient of relative risk aversion. ${ }^{20}$ This limits the amount of equilibrium risk shifting. The value of 1.5 chosen for the coefficient of relative risk aversion makes agents only moderately risk averse, in the sense that their momentary utility functions are only slightly more concave than the logarithmic case. Third, the amount of risk shifting possible is limited by the fact that entrepreneurs constitute only a small proportion of the population.

Two additional experiments were run to see how these factors affect the volume of insurance transactions. In the first, the coefficient of relative risk aversion for workers was increased to 10 . At the same time the standard deviation for the innovation to the technology shock was increased from 0.77 to 0.94 percent; this was done to prevent the variability of output from falling. ${ }^{21}$ With this new configuration of parameter values, output's standard deviation remained the same at 1.60 percent, while consumption's and productivity's rose to 0.74 and 0.95 , and the ones for investment and hours fell to 4.16 and 0.67 . The volume of insurance transactions rose from 1.0 percent to about 4.5 percent of output. In the second experiment, entrepreneurs were taken to comprise the upper 5 percent of the wealth distribution, rather than the top 1 percent. In line with the stylized facts on the distribution of wealth in the U.S., it was assumed that this segment of the population holds 50 percent of aggregate wealth. [Again see Wolff and Marley (1989).] Once again, workers were assumed to have a coefficient of relative risk aversion of 10 . The value of insurance transactions in this case amounted to 5.0 percent of output.

\footnotetext{
${ }^{20}$ The coefficients $\gamma$ and $\varphi$ probably are not good measures of risk aversion in the model. It may be better to gauge the degree of concavity in each agent's value function by computing $\left|b V_{11} / V_{1}\right|$ and $\left|a J_{11} / J_{1}\right|$ at the steady state. These objects derive from each agent's decision problem and are difficult to compute using the solution algorithm employed here that directly attacks the conditions characterizing the model's general equilibrium.

${ }^{21}$ As was mentioned above, as the coefficient of relative risk aversion is increased (or equivalently the elasticity of intertemporal substitution decreased) fluctuations in macroaggregates diminish. This can be compensated for by increasing the amount of volatility in the technology shock. There are limits on this process since eventually the standard deviation for the technology shock will depart too far from what is observed in the data. Also, Mehra and Prescott (1985) suggest that 10 is the upper bound on reasonableness for the coefficient of relative risk aversion.
} 


\section{Conclusions}

A dynamic, stochastic general equilibrium model with heterogeneous agents was constructed to study the allocation of risk and the distribution of income over the business cycle. Specifically, in the model formulated there were two types of agents, namely workers and entrepreneurs. Entrepreneurs provided workers with insurance against cyclical risk. Agents had preferences in line with Epstein's (1983) notion of stationary cardinal utility. This allowed the model to possess a unique, invariant long-run distribution of wealth across agents. The constructed model was parameterized, calibrated, and simulated to see whether it could mimic some stylized facts of the postwar U.S. economy such as the countercyclical movement in labor's share of income over the business cycle and the acyclical behavior of real wages.

The findings can be summarized as follows: It was found that optimal labor contracting could account, quantitatively, for the observed pattern of fluctuations in labor income. Measured labor income includes insurance and savings components that tend to move countercyclically over the business cycle, and which operate to counterbalance the procyclical movement in the marginal product of labor. The flow of transactions involving insurance against cyclical risk were measured to be about 1 percent of output for the benchmark model. This compared with an estimate for the U.S. economy of 0.7 percent. The size of this number is limited by the fact that the amount of observed cyclical variability in macroaggregates for the postwar U.S. economy is small. Finally, the variable discount factor worked to increase the volatility in macroaggregates. The procyclical movement in the endogenous discount factor increased the amount of intertemporal substitution in the model by enticing investment and work effort in booms and discouraging them in slumps.

\section{Appendix A: Labor income in OECD countries}

Some stylized facts concerning the cyclical behavior of labor's share of income and real wages in OECD countries will be presented here. The choice of countries and the time periods used was governed by the availability of data. Labor's share of income was defined to be compensation of employees divided by aggregate income. Aggregate income was taken to be either GNP or GDP, the latter used when GNP was unavailable. The data used was taken from OECD Quarterly National Accounts. The data on wages came from International Financial Statistics which reports indices measuring wage payments in various countries. These indices were deflated by the GNP or GDP deflators for the country concerned. Here, the data on income and the price level was also taken from the International Financial Statistics. Some countries report seasonally unadjusted data, others seasonally adjusted. To make the series comparable, all 
Table 6

Labor's share of income, 1971-1989:3

\begin{tabular}{llllllllrrr}
\hline \multicolumn{1}{l}{$\operatorname{Corr}\left(l s i_{i+j}, y_{t}\right)$} \\
\cline { 2 - 10 } Country & $j=-4$ & $j=-3$ & $j=-2$ & $j=-1$ & $j=0$ & $j=+1$ & $j=+2$ & $j=+3$ & $j=+4$ \\
\hline Australia & -0.43 & -0.56 & -0.61 & -0.59 & -0.52 & -0.23 & 0.05 & 0.27 & 0.42 \\
Austria & -0.18 & -0.29 & -0.47 & -0.51 & -0.63 & -0.39 & -0.09 & 0.15 & 0.46 \\
Britain & -0.38 & -0.43 & -0.45 & -0.41 & -0.49 & -0.11 & 0.10 & 0.17 & 0.30 \\
Canada & -0.26 & -0.42 & -0.52 & -0.56 & -0.54 & -0.34 & -0.12 & 0.06 & 0.16 \\
France & -0.38 & -0.54 & -0.61 & -0.66 & -0.72 & -0.51 & -0.29 & -0.07 & 0.17 \\
Germany & -0.62 & -0.69 & -0.67 & -0.58 & -0.42 & -0.14 & 0.15 & 0.42 & 0.62 \\
Japan & -0.13 & -0.39 & -0.62 & -0.78 & -0.85 & -0.74 & -0.59 & -0.38 & -0.12 \\
USA & -0.34 & -0.37 & -0.41 & -0.38 & -0.35 & -0.06 & 0.20 & 0.37 & 0.45 \\
\hline
\end{tabular}

Table 7

Real wage

\begin{tabular}{lcl}
\hline Country & Corr $\left(w_{t}, y_{t}\right)$ & Sample \\
\hline Australia & -0.08 & $1961: 3-91: 1$ \\
Austria & -0.09 & $1964: 1-90: 4$ \\
Britain & 0.26 & $1963: 1-91: 1$ \\
Canada & -0.24 & $1957: 1-91: 1$ \\
France & -0.21 & $1970: 1-90: 1$ \\
Germany & 0.39 & $1960: 1-90: 3$ \\
Israel & 0.08 & $1982: 1-90: 4$ \\
Italy & 0.13 & $1960: 1-90: 3$ \\
Japan & -0.31 & $1957: 1-91: 1$ \\
Sweden & 0.06 & $1980: 1-89: 4$ \\
USA & 0.36 & $1957: 1-91: 2$ \\
\hline
\end{tabular}

seasonally unadjusted data was adjusted using the Census X-11 method. The correlations between labor's share of income, $l s i$, and real wages, $w$, on the one hand, and income, $y$, on the other are given in Tables 6 and 7 (where all variables have been H-P filtered).

\section{Appendix B: Relative incomes - U.S. economy}

The worth of an entrepreneur's time relative to a worker's was calculated using annual data on the U.S. distribution of income for the years 1979 to $1990{ }^{22}$ It is well known that the tail (or upper end) of the income distribution is approximately Pareto. 
Let $F:[1, \infty] \rightarrow[0,1]$ represent the Pareto distribution function. The function $F$ has a simple characterization:

$$
F(x)=1-(x / b)^{-\alpha}, \quad \text { for } \quad x \geq b, \quad \alpha>0 .
$$

In the current context $x$ represents the level of labor income and $F(x)$ the fraction of individuals who earn no more than this amount. Now, a convenient property of the Pareto distribution is that

$$
\mathrm{E}[x \mid x \geq c]=[\alpha /(\alpha-1)] c, \text { for } \alpha>1
$$

From Eq. (B.1) the cutoff level of income separating the top one percent of the population from the bottom 99 percent is $F^{-1}(0.99)$. Thus, from (B.2) the mean level of income for the top one percent is given by

$$
\mathrm{E}\left[x \mid x \geq F^{-1}(0.99)\right]=[\alpha /(\alpha-1)] F^{-1}(0.99) .
$$

The mean level of earnings for the bottom 99 percent is then

$$
\mathrm{E}\left[x \mid x \leq F^{-1}(0.99)\right]=(1 / 0.99) \mathrm{E}[x]-(0.01 / 0.99) \mathrm{E}\left[x \mid x \geq F^{-1}(0.99)\right] .
$$

Therefore, the average income earned by the top one percent is $E[x \mid$ $\left.x \geq F^{-1}(0.99)\right] / \mathrm{E}\left[x \mid x \leq F^{-1}(0.99)\right]$ times greater than the average income earned by the bottom 99 percent.

For the year 1990 the average income earned by a person working in the U.S. was $\$ 21,197$. Hence, $E[x]=\$ 21,197$. To calculate the average income for the top one percent requires estimating the distribution function defincd by (B.1). Observe that

$$
\ln (1-F(x))=\alpha \ln b-\alpha \ln x .
$$

\footnotetext{
${ }^{22}$ The source for the data was the Current Population Reports: Money Income of Households, Families and Persons in the U.S., which is a publication of the U.S. Department of Commerce. Due to limitations in the availability of the published data, the analysis could only be conducted for the years 1979 to 1990 . The published data reports labor income distribution statistics taken from a sample of individuals. The sample used contained individuals taken from all races and both sexes and included both full- and part-time workers.
} 


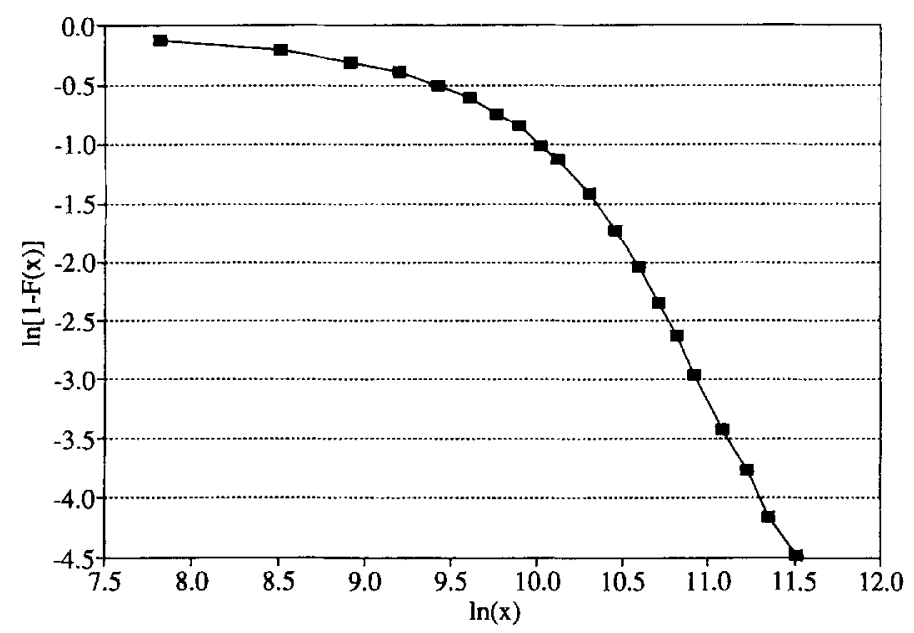

Fig. 5. Relationship between $\ln (1-F(x))$ and $\ln (x)$, U.S. data for 1990.

Fig. 5 plots the relationship between $\ln (1-F(x))$ and $\ln (x)$ that is observed in the U.S. data for the year 1990. Observe that the tail of the curve is linear and thus can be well approximated by (B.5). Fitting a linear regression of the form $\ln (1-F(x))=\alpha \ln b-\alpha \ln x$ to the last eight observations yielded the following estimates:

\begin{tabular}{lrll}
\hline Constant & $\alpha$ & $R^{2}$ & $D W$ \\
\hline 26.90 & $\begin{array}{c}2.73 \\
(47.69)\end{array}$ & 0.9969 & 2.07 \\
$(42.56)$ & & \\
\hline
\end{tabular}

By using these estimates, $F^{-1}(0.99)$ was computed to be $\$ 101,968$. The average income of the top one percent was calculated, using (B.3), to have a value of $\$ 160,859$. From (B.4), it then transpires that the average income of the bottom 99 percent was $\$ 19,786$. Thus, the top one percent earned 8.12 times as much as the bottom 99 percent did in 1990. By performing similar calculations for the years 1979 to 1989 , this ratio was estimated on average to be 8.21 .

\section{Appendix C: Solution algorithm}

Let the system of Eqs. (6), (8), (9), (10), (12), (13), and (15) defining a solution to the model be more compactly represented by [remember that there are $q$ copies 
of each of Eqs. (8) and (13)]

$$
\begin{aligned}
& \Delta\left[b(\lambda), k, V, J, \vec{b}^{\prime}\left(\vec{\lambda}^{\prime}\right), k^{\prime}, l, h, \vec{p}\left(\vec{\lambda}^{\prime}\right) ; \lambda\right] \\
& =\int \Omega\left[b^{\prime}\left(\lambda^{\prime}\right), k^{\prime}, V^{\prime}, J^{\prime}, \vec{b}^{\prime \prime}\left(\vec{\lambda}^{\prime \prime}\right), k^{\prime \prime}, l^{\prime}, h^{\prime}, \vec{p}^{\prime}\left(\vec{\lambda}^{\prime \prime}\right) ; \lambda, \lambda^{\prime}\right] \mathrm{d} \dot{\lambda}^{\prime} .
\end{aligned}
$$

Here, $\Delta: R^{2 q+8} \rightarrow R^{2 q+5}$ and $\Omega: R^{2 q+8} \rightarrow R^{2 q+5}$. In order to simulate the model, a set of value functions, policy rules, and price functions of the form $V=V[b(\lambda), k, \lambda], \quad J=J[b(\lambda), k, \lambda], \quad \vec{b}^{\prime}\left(\hat{\lambda}^{\prime}\right)=b^{\prime}[b(\hat{\lambda}), k, \lambda], \quad k^{\prime}=k^{\prime}[b(\lambda), k, \lambda]$, $l=l[b(\lambda), k, \lambda], h=h[b(\lambda), k, \lambda]$, and $\vec{p}\left(\dot{\lambda}^{\prime}\right)=\vec{p}[b(\lambda), k, \lambda]$, must be found. Note that $\vec{b}^{\prime}\left(\vec{\lambda}^{\prime}\right)$ and $\vec{p}\left(\vec{\lambda}^{\prime}\right)$ are vector functions whose $i$ th components read, respectively, as $b^{\prime}\left(\lambda^{i^{\prime}}\right)=b^{\prime}\left[\lambda^{i^{\prime}} ; b(\lambda), k, \lambda\right]$, and $p\left(\lambda^{i^{\prime}}\right)=p\left[\lambda^{i^{\prime}} ; b(\lambda), k, \lambda\right]$. To do this, an algorithm developed by Coleman (1991) will be employed that approximates the true solution functions over a grid using a multilinear interpolation scheme. ${ }^{23}$

To begin, restrict the permissible range of values for the capital stock, holdings of contingent claims, and the technology shock to be in the closed intervals $\left[b_{1}, b_{m}\right],\left[k_{1}, k_{n}\right]$, and $\left[\lambda_{1}, \lambda_{r}\right]$, respectively, and let $B=\left\{b_{1}, b_{2}, \ldots, b_{m}\right\}$, $K=\left\{k_{1}, k_{2}, \ldots, k_{n}\right\}$, and $L=\left\{\lambda_{1}, \lambda_{2}, \ldots, \lambda_{r}\right\}$ represent sets of monotonically increasing grid points that span these intervals. Next, make an initial guess for the value of the function $z=z[b(\lambda), k, \lambda]$, for $z=V, J, b^{\prime}\left(\lambda^{1^{\prime}}\right), \ldots, b^{\prime}\left(\lambda^{q^{\prime}}\right)$, $k^{\prime}, l, h$, and $p\left(\lambda^{1^{\prime}}\right), \ldots, p\left(\lambda^{q^{\prime}}\right)$, at each of the $m n r$ points in the set $B \times K \times L$. Denote the value for the initial guess of the function $z$ at the point $\left[b_{h}, k_{i}, \lambda_{j}\right]$ by $z^{0}\left[b_{h}, k_{i}, \lambda_{j}\right]$. A guess for $z$ at other points in its domain $\left[b_{1}, b_{m}\right] \times\left[k_{1}, k_{n}\right] \times\left[\lambda_{1}, \lambda_{r}\right]$ is then constructed through multilinear interpolation (see Press et al., 1986). Specifically, take some point $[b(\lambda), k, \lambda] \in\left[b_{1}, b_{m}\right] \times\left[k_{1}, k_{n}\right] \times\left[\lambda_{1}, \lambda_{r}\right]$. The value of the function $z^{0}$ at the point $[b(\lambda), k, \lambda]$, or $z^{0}[b(\hat{\lambda}), k, \lambda]$, is defined as follows:

$$
\begin{aligned}
z^{0}[b(\lambda), k, \lambda]= & (1-u)(1-v)(1-w) z^{0}\left[b_{h}, k_{i}, \lambda_{j}\right] \\
& +u(1-v)(1-w) z^{0}\left[b_{h+1}, k_{i}, \lambda_{j}\right]+u v(1-w) \\
& \times z^{0}\left[b_{h+1}, k_{i+1}, \lambda_{j}\right]+(1-u) v(1-w) z^{0}\left[b_{h}, k_{i+1}, \lambda_{j}\right] \\
& +(1-u)(1-v) w z^{0}\left[h_{h}, k_{i}, \lambda_{j+1}\right] \\
& +u(1-v) w z^{0}\left[b_{h+1}, k_{i}, \lambda_{j+1}\right]+u v w z^{0}\left[b_{h+1}, k_{i+1}, \lambda_{j+1}\right] \\
& +(1-u) v w z^{0}\left[b_{h}, k_{i+1}, \lambda_{j+1}\right],
\end{aligned}
$$

\footnotetext{
${ }^{23}$ Coleman's (1991) technique is related to one developed by Baxter (1991) and Danthine and Donaldson (1991). The principle difference between Coleman's on the one hand and Baxter's and Danthine and Donaldson's on the other is that the latter restrict the range of the functions describing the laws of motion for the state variables to lie on a grid, while the former does not.
} 
where the weights $u, v$, and $w$ are given by

$$
u=\frac{b(\lambda)-b_{h}}{b_{h+1}-b_{h}}, \quad v=\frac{k-k_{i}}{k_{i+1}-k_{i}}, \quad w=\frac{\lambda-\lambda_{j}}{\lambda_{j+1}-\lambda_{j}}
$$

and the grid points $b_{h}, b_{h+1}, k_{i}, k_{i+1}, \lambda_{j}$, and $\lambda_{j+1}$ being chosen such that

$$
b_{h} \leq b(\lambda) \leq b_{n+1}, \quad k_{i} \leq k \leq k_{i+1}, \quad \lambda_{j} \leq \lambda \leq \lambda_{j+1} .
$$

Thus, the interpolated value of $z^{0}$ at $[b(\lambda), k, \lambda]$, is simply taken to be a weighted average of its values at the eight nearest grid points. Note that the interpolated function $z^{0}$ is continuous on $\left[b_{1}, b_{m}\right] \times\left[k_{1}, k_{n}\right] \times\left[\lambda_{1}, i_{r}\right]$.

Given initial guesses for the functions $V, J, \vec{b}^{\prime}\left(\vec{\lambda}^{\prime}\right), k^{\prime}, l, h$, and $\vec{p}\left(\vec{\lambda}^{\prime}\right)$, denoted by $V^{0}, J^{0}, \vec{b}^{0}\left(\vec{\lambda}^{\prime}\right), k^{0^{\prime}}, l^{0}, h^{0}$, and $\vec{p}^{0}\left(\vec{\lambda}^{\prime}\right)$, respectively, it is straightforward to compute revised guesses $V^{1}, J^{1}, \vec{b}^{1}\left(\vec{\lambda}^{\prime}\right), k^{1^{\prime}}, l^{1}, h^{1}$, and $\vec{p}^{1}\left(\vec{\lambda}^{\prime}\right)$. Note that the $q$ components of the vector functions $\vec{b}^{0^{\prime}}\left(\vec{\lambda}^{\prime}\right)$ and $\vec{p}^{0}\left(\vec{\lambda}_{i}^{\prime}\right)$ are simply $b^{0^{\prime}}\left(\hat{\lambda}^{1^{\prime}}\right), \ldots, b^{0^{\prime}}\left(\lambda^{q^{\prime}}\right)$, and $p^{0}\left(\lambda^{1^{\prime}}\right), \ldots, p^{0}\left(\lambda^{q^{\prime}}\right)$. Now for each point $\left(b_{h}, k_{i}, \lambda_{j}\right) \in B \times K \times L$ values for $V^{1}\left(b_{h}, k_{i}, \lambda_{j}\right), J^{1}\left(b_{h}, k_{i}, \lambda_{j}\right), \vec{b}^{1}\left(b_{h}, k_{i}, \dot{\lambda}_{j}\right), k^{1^{\prime}}\left(b_{h}, k_{i}, \lambda_{j}\right), l^{1}\left(b_{h}, k_{i}, \lambda_{j}\right), h^{1}\left(b_{h}, k_{i}, \lambda_{j}\right)$, and $\vec{p}^{1}\left(b_{h}, k_{i}, \lambda_{j}\right)$ can be computed by solving the nonlinear system of equations shown below for $V, J, \vec{b}^{\prime}\left(\vec{\lambda}^{\prime}\right), k^{\prime}, l, h$, and $\vec{p}\left(\vec{\lambda}^{\prime}\right)$,

$$
\begin{aligned}
& A\left[b_{h}, k_{i}, V, J, \vec{b}^{\prime}\left(\vec{\lambda}^{\prime}\right), k^{\prime}, l, h, \vec{p}^{\prime}\left(\vec{\lambda}^{\prime}\right) ; \lambda_{j}\right] \\
& =\sum_{d=1}^{q} \Omega\left[b^{\prime}\left(\lambda^{d^{\prime}}\right), k^{\prime}, V^{0^{\prime}}, J^{0^{\prime}}, \vec{h}^{0^{\prime \prime}}\left(\vec{\lambda}^{0^{\prime \prime}}\right), k^{0^{\prime \prime}}, l^{0^{\prime}}, h^{0^{\prime}}, \vec{p}^{0^{\prime}}\left(\vec{\lambda}^{0^{\prime \prime}}\right): \lambda_{j}, \lambda^{d^{\prime}}\right],
\end{aligned}
$$

where, for instance, $V^{0^{\prime}}=V^{0}\left(b^{\prime}\left(\lambda^{d^{\prime}}\right), k^{\prime}, \lambda^{d^{\prime}}\right)$ and $\vec{b}^{0^{\prime \prime}}\left(\vec{\lambda}^{\prime \prime}\right)=b^{0^{\prime}}\left(b^{\prime}\left(\lambda^{d^{\prime}}\right), k^{\prime}, \lambda^{d^{\prime}}\right)$. This represents a system of $2 q+5$ equations in $2 q+5$ unknowns which can be solved numerically using Newton's method. In practice a generalized secant method is employed first to obtain good initial guesses for Newton's procedure. [See Ortega and Rheinboldt (1970) for more details.] Given values for $k^{\prime}, b^{\prime}$, and $i^{\prime}$ at each of the $m n r$ grid points in $B \times K \times L$, the functions $V^{1}, J^{1}, \vec{b}^{1}\left(\vec{\lambda}^{\prime}\right), k^{1^{\prime}}, l^{1}, h^{1}$, and $\vec{p}^{1}\left(\vec{\lambda}^{\prime}\right)$ can be extended over the entire domain $\left[b_{1}, b_{m}\right] \times\left[k_{1}, k_{n}\right] \times\left[\lambda_{1}, \lambda_{r}\right]$ via interpolation, as was done previously. The functions $V^{1}, J^{1}, \vec{b}^{1}\left(\vec{\lambda}^{\prime}\right), k^{1^{\prime}}, l^{1}, h^{1}$, and $\vec{p}^{1}\left(\vec{\lambda}^{\prime}\right)$ are then used as guesses on the next iteration, with the whole procedure being repeated until the decision rules have converged.

The functions characterizing the model's general equilibrium were interpolated over grids with five points for each of the three state variables: capital, claims, and the technology shock. Fig. 6 illustrates the value function for the entrepreneur, which is drawn in the capital-claims space holding fixed the value of the technology shock at one. This value function is increasing in the amount 


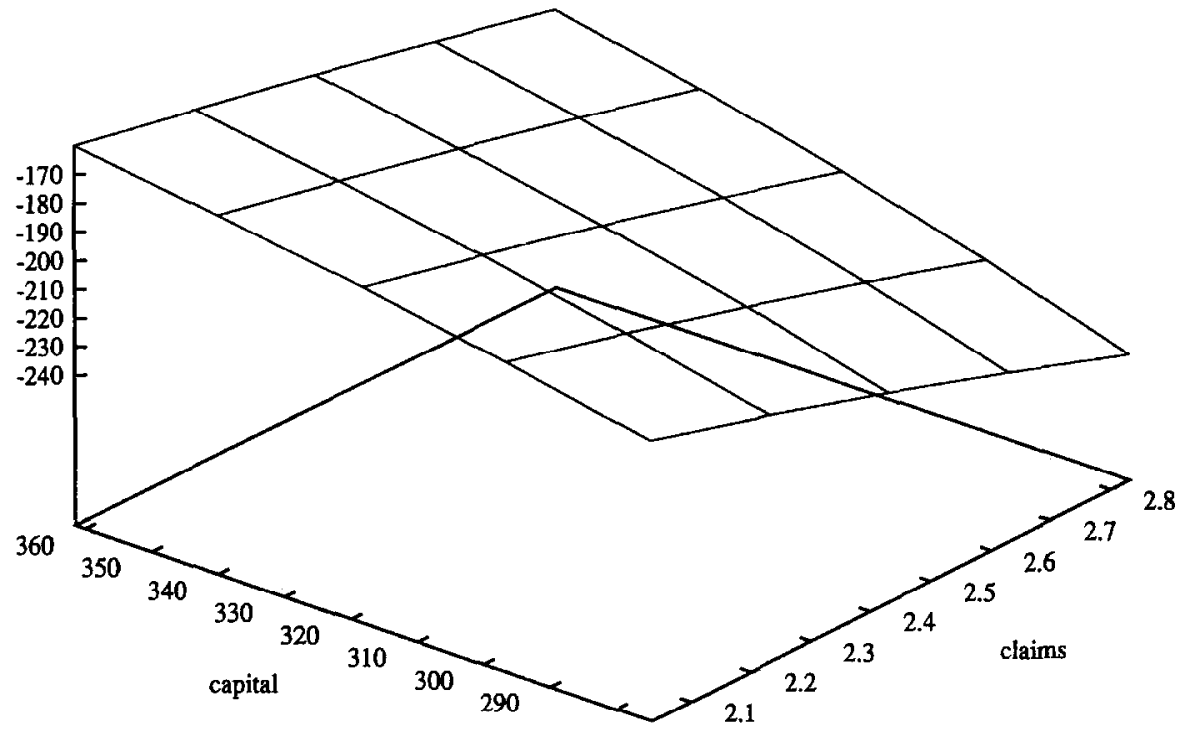

Fig. 6. Entrepreneur's value function $(\lambda=1)$.

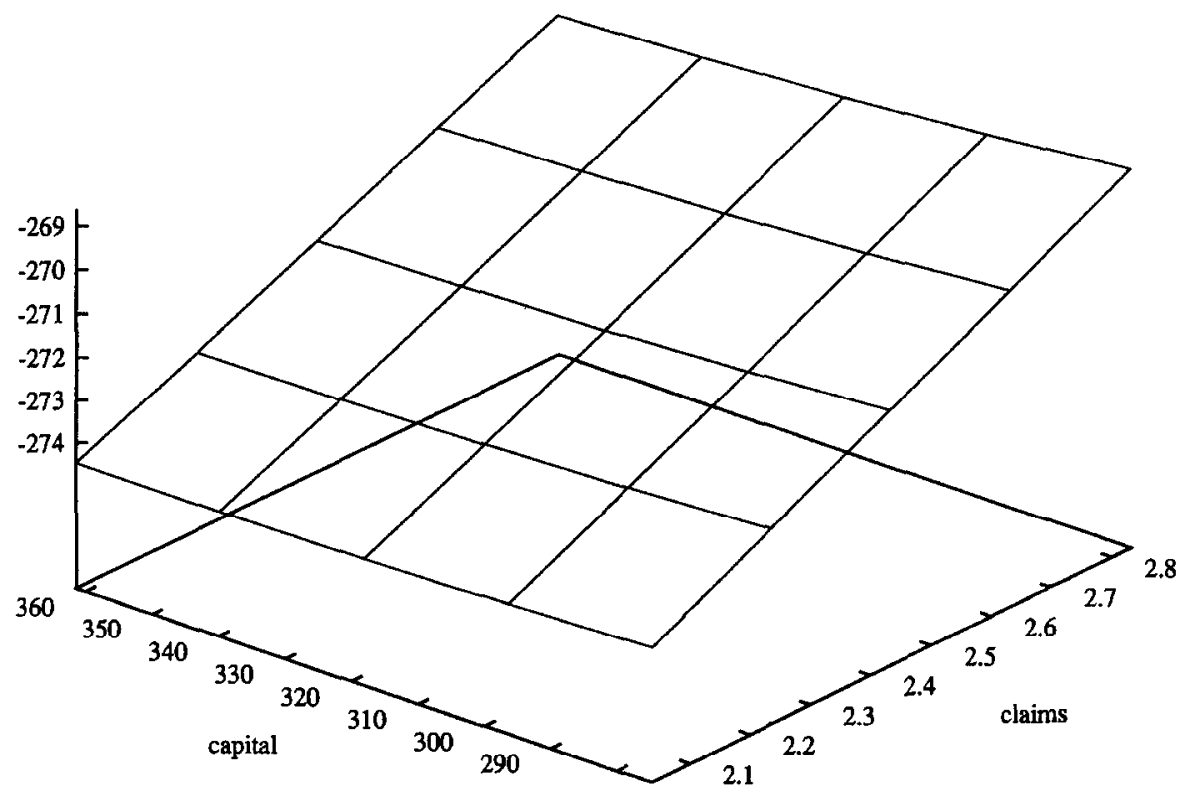

Fig. 7. Worker's value function $(\hat{\lambda}=1)$. 
of capital owned by entrepreneurs and decreasing in the amount of debt owed to workers; it is also strictly concave. The worker's value function is shown in Fig. 7. It is increasing in his level of wealth (claims). Somewhat surprisingly, however, it is not increasing in the capital stock. Neither is it strictly concave. This can be readily explained as follows: First, recall that the capital stock is not a decision variable for the worker. Thus, there should be no presumption that his value function should be jointly concave in capital and claims. It is concave in his holdings of claims, however, as should be expected. Second, imagine increasing the economy's capital stock, holding fixed the state of technology and the quantity of claims held by workers. This has two opposing effects on the worker's welfare. On the one hand, his welfare increases since labor's marginal product rises. On the other hand, his welfare falls since a lower return is now earned on savings. The net effect is ambiguous.

Once the decision rules have been obtained the model can be simulated and various sample statistics for variables of interest computed. This is discussed in further detail in Section 6.

\section{References}

Azariadis, Costas, 1978, Escalator clauses and the allocation of cyclical risks, Journal of Economic Theory 18, 119-155.

Baxter, Marianne, 1991, Approximating suboptimal dynamic equilibria: An Euler equation approach, Journal of Monetary Economics 28, 173-200.

Bencivenga, Valerie R., 1992, An econometric study of hours and output variations with preference shocks, International Economic Review 33, 449-471.

Benhabib, Jess, Richard Rogerson, and Randall Wright, 1991, Homework in macroeconomics: Household production and aggregate fluctuations, Journal of Political Economy 99, 1166-1187.

Bils, Mark and Jang-Ok Cho, 1992, Cyclical factor utilization, Unpublished paper (Department of Economics, University of Rochester, Rochester, NY).

Blanchard, Olivier Jean and Stanley Fischer, 1989, Lectures on macroeconomics (MIT Press, Cambridge, MA).

Cho, Jang-Ok and Richard Rogerson, 1987, Risk sharing, indivisible labor and aggregate fluctuations, Discussion paper 87-23 (Department of Economics, Southern Illinois University, Carbondale, IL); Cuadernos Economicos, forthcoming.

Christiano, Lawrence J. and Martin Eichenbaum, 1992, Current real business cycle theories and aggregate labor market fluctuations, American Economic Review 82, 430-450.

Coleman, Wilbur John, 1991, Equilibrium in an economy with capital and taxes on production, Econometrica 59, 1091-1104.

Costello, Donna M. and J. Praschnik, 1992, Are labor shares really constant? An international study of the cyclical behavior of labor shares, Research report 9207 (Department of Economics, University of Western Ontario, London).

Danthine, Jean-Pierre and John B. Donaldson, 1991, Risk sharing, the minimum wage, and the business cycle, in: William A. Barnett, Bernard Cornet, Claude D'Aspremont, Jean Gabszewicz, and Andreu Mas-Collel, eds., Equilibrium theory and applications (Cambridge University Press, Cambridge) $299-318$. 
Danthine, Jean-Pierre and John B. Donaldson, 1992, Risk sharing in the business cycle, European Economic Review 36, 468-475.

Dunlop, John T., 1938. The movement of real and money wage rates, The Economic Journal 48, 413-434.

Epstein, Larry G., 1983, Stationary cardinal utility and optimal growth under uncertainty, Journal of Economic Theory 31, 132-152.

Hansen, Gary D., 1985, Indivisible labor and the business cycle, Journal of Monetary Economics 16, 309-328.

Hansen, Gary D. and Randall Wright, 1992, The labor market in real business cycle theory, Federal Reserve Bank of Minneapolis Quarterly Review 16, 2-12.

Kydland, Finn E. and Edward C. Prescott, 1982, Time to build and aggregate fluctuations, Econometrica 50, 1345-1370.

Kydland, Finn E. and Edward C. Prescott, 1990, Business cycles: Real facts and a monetary myth, Federal Reserve Bank of Minneapolis Quarterly Review 14, 3-18.

Long, John B. and Charles I. Plosser, 1983, Real business cycles, Journal of Political Economy 91 , 39-69.

Lucas, Robert E., Jr., 1990, Supply-side economics: An analytical review, Oxford Economic Papers 42, 293-316.

Lucas, Robert E., Jr. and Nancy L. Stokey, 1984, Optimal growth with many consumers, Journal of Economic Theory 32, 139-171.

Mehra, Rajnish and Edward C. Prescott, 1985, The equity premium: A puzzle, Journal of Monetary Economics 15, 145-161.

Mendoza, Enrique G., 1991, Real business cycles in a small open economy, American Economic Review 81, 797-818.

Ortega, James M. and Werner C. Rheinboldt, 1970, Iterative solution of nonlinear equations in several variables (Academic Press, New York, NY).

Prescott, Edward C., 1986, Theory ahead of business cycle measurement, Federal Reserve Bank of Minneapolis Quarterly Review 10, 9-22.

Press, William H., Brian P. Flannery, Saul A. Teukolsky, and William T. Vetterling, 1986, Numerical recipes: The art of scientific computing (Cambridge University Press, Cambridge).

Rebelo, Sergio, 1988, Tractable heterogeneity and near steady state dynamics, Unpublished paper (Department of Finance, J.L. Kellogg Graduate School of Management, Northwestern University, Evanston, IL).

Romer, Paul M., 1989, Capital accumulation in the theory of long-run growth, in: Robert J. Barro, ed., Modern business cycle theory (Harvard University Press, Cambridge, MA) 51-127.

Summers, Lawrence H., 1986, Some skeptical observations on real business cycle theory, Federal Reserve Bank of Minneapolis Quarterly Review 10, 23-27.

Tarshis, Lorie, 1939, Changes in real and money wages, The Economic Journal 49, 150-154.

Wolff, Edward N. and Marcia Marley, 1989, Long term trends in U.S. wealth inequality: Methodological issues and results, in: Robert Lipsey and Helen Tice, eds., Saving, investment, and wealth (University of Chicago Press, Chicago, IL) 765-839.

Wright, Randall D., 1988, The observational implications of labor contracts in a dynamic general equilibrium model, Journal of Labor Economics 6, 530-551. 